\title{
Conceptualising, operationalising, and measuring trust in participatory health research networks: a scoping review
}

\author{
Meghan Gilfoyle, Anne MacFarlane and Jon Salsberg* (1)
}

\begin{abstract}
Background: There are many described benefits of community-based participatory research (CBPR), such as increased relevance of research for those who must act on its findings. This has prompted researchers to better understand how CBPR functions to achieve these benefits through building sustainable research partnerships. Several studies have identified "trust" as a key mechanism to achieve sustainable partnerships, which themselves constitute social networks. Although existing literature discusses trust and CBPR, or trust and social networks, preliminary searches reveal that none link all three concepts of trust, CBPR, and social networks. Thus, we present our scoping review to systematically review and synthesize the literature exploring how trust is conceptualised, operationalised, and measured in CBPR and social networks.
\end{abstract}

Methods: This review follows the guidance and framework of Peters et al. which is underpinned by the widely used framework of Levac and colleagues. Levac and colleagues provided enhancements to the methodological framework of Arksey and O'Malley. We explored several electronic databases including Scopus, Medline, PubMed, Web of Science, CINAHL, Cochrane Library, Google Scholar, and PsychINFO. A search strategy was identified and agreed upon by the team in conjunction with a research librarian. Two independent reviewers screened articles by title and abstract, then by full-text based on pre-determined exclusion/inclusion criteria. A third reviewer arbitrated discrepancies regarding inclusions/exclusions. A thematic analysis was then conducted to identify relevant themes and sub-themes.

Results: Based on the 26 extracted references, several key themes and sub-themes were identified which highlighted the complexity and multidimensionality of trust as a concept. Our analysis revealed an additional emergent category that highlighted another important dimension of trust—outcomes pertaining to trust. Further, variation within how the studies conceptualised, operationalised, and measured trust was illuminated. Finally, the multidimensionality of trust provided important insight into how trust operates as a context, mechanism, and outcome.

Conclusions: Findings provide support for future research to incorporate trust as a lens to explore the social-relational aspects of partnerships and the scope to develop interventions to support trust in partnerships.

Keywords: Community-based participatory research, Trust, Social networking, Patient participation, Community participation, Review

*Correspondence: Jon.Salsberg@ul.ie

Public \& Patient Involvement Research Unit, School of Medicine and Health Research Institute (HRI), University of Limerick, Limerick, Ireland V94 T9PX

\begin{abstract}
Background
Participatory research $(\mathrm{PR})$ is defined as the "systematic inquiry, with the collaboration of those affected by the issue being studied, for the purposes of education and taking action or effecting change" [1]. In recent decades, participatory research (PR) has been gaining recognition
\end{abstract} original author(s) and the source, provide a link to the Creative Commons licence, and indicate if changes were made. The images or other third party material in this article are included in the article's Creative Commons licence, unless indicated otherwise in a credit line to the material. If material is not included in the article's Creative Commons licence and your intended use is not permitted by statutory regulation or exceeds the permitted use, you will need to obtain permission directly from the copyright holder. To view a copy of this licence, visit http://creativecommons.org/licenses/by/4.0/. The Creative Commons Public Domain Dedication waiver (http://creativeco mmons.org/publicdomain/zero/1.0/) applies to the data made available in this article, unless otherwise stated in a credit line to the data. 
throughout research communities as an approach that serves to bridge the gap between research and practice $[2,3]$. Specifically, PR helps to maximise the relevancy of research and usability of its products, while simultaneously building capacity and addressing issues of social justice and self-determination among end-user communities [2, 3]. Currently, an overarching theory of PR does not exist, underscoring the need for greater knowledge of the key concepts and mechanisms of participatory research.

This is challenging as there are many different labels that exist that fall within the realm of participatory research, (e.g., public and patient involvement, participatory health research, participatory action research), all striving to bridge this gap between knowledge and practice by promoting inclusivity, while ensuring all partners who the research serves to benefit are actively engaged in the research process [3].

Despite this challenge, there have been important advancements towards theory development in PR. One such advancement comes from one of the more widely recognized bodies of literature within PR falling under the heading of community-based participatory research (CBPR), with core philosophy and values grounded in social and environmental justice and self-determination to address inequities, particularly in regards to health [3]. Similarly, the W.K. Kellogg Foundation's Community Health Scholars Program [4] defines CBPR as:

\section{A collaborative approach to research that equitably involves all partners in the research process and rec- ognizes the unique strengths that each brings. CBPR begins with a research topic of importance to the community with the aim of combining knowledge and action for social change to improve community health and eliminate health disparities [4].}

For this scoping review, we will use the term CBPR as an all-encompassing term, which like PR, will incorporate a broad range of terms (e.g., public and patient involvement, participatory health research, participatory action research), that embrace shared core philosophies and values. CBPR was chosen as the term of choice for this review given its wide recognition across the literature, and its associated conceptual model $[2,3,5]$.

Specifically, a CBPR conceptual model was developed [5] and adapted [2] which provides a concrete framework for understanding how the CBPR process is influenced by contextual and process-related aspects that can affect the ability to achieve both intermediate impacts (e.g. stronger partnerships) and long-term outcomes (e.g. improved health, community transformation, and health equity) [6]. The CBPR conceptual model was deemed appropriate for addressing key gaps in the literature because of its comprehensive nature and its focus on the relationship between context, process dynamics, and research outcomes [7]. These gaps include theoretically and empirically explaining "how contexts, partnership practices, and research/intervention engagement factors contribute to broad-based CBPR and health outcomes" [7]. Oetzel et al. [7] empirically tested variables of the CBPR model, with the aim "to better understand the mechanisms for impact on achieving" intermediate and long-term health outcomes, such as community transformation. Findings from this study found that the model was suitable for explaining important relational (e.g. interactive) and structural (e.g. team composition and nature) processes [2] and pathways for impact on intermediate and longterm outcomes [7].

With an emphasis on the relational aspect of the CBPR model, a systematic review by Jagosh et al. [8] identified partnership synergy as a universal feature of the collaborative process necessary for building and sustaining partnerships that create resilience, sustain health-related goals, and extend program infrastructure, while creating new and unexpected ideas and outcomes. Literature from the community perspective includes various accounts of community problems of engagement and trust. Jagosh et al. [9], for example, identify instances where contextual factors such as history of oppression or research abuse have triggered mistrust in the community, impacting positive outcomes, such as partnership synergy. Jagosh et al. [9] further explored what supports partnership synergy in successful long-term CBPR partnerships. The building and maintenance of trust was identified as a key mechanism in this process. However, Jagosh et al. [9] treated trust as a "black box" concept without unpacking its internal dimensions and processes. This limits understanding/progress because if there is no clear conceptualisation of trust then it is challenging to operationalise or measure it in real-world partnerships.

Therefore, it is valuable to explore how trust is conceptualised, operationalised, and measured in CBPR partnerships. To do this, a methodology must be adopted that supports the analysis of trust in CBPR partnerships.

It is necessary to describe and measure trust among and between research partners within CBPR. Conceptually, a social network can be seen as a set of connections between individuals or organisations. This is similar to a partnership, where individuals or organisations are connected around a common purpose [10]. Social network analysis (SNA) is a methodology for describing and measuring contextual and relational dynamics among and between social actors [11]. SNA provides tools for investigating the development and maintenance of trust and trustworthiness and their effects on partnership functioning within social 
networks [12]. The potential value here is, for example, as a CBPR project unfolds, the ability to measure trust can allow for the design of structural interventions (e.g. adding or removing planned working meetings) to improve trust and partnership function by supporting context or social structures within the partnership [8, 9].

Social networks have been used to explore trust in diverse fields, such as in health [13] or education [14]. They have also been used to explore dynamics within CBPR $[15,16]$. However, social networks have not been used to explore the dynamics of trust within CBPR. Therefore, CBPR, social networks, and trust (Fig. 1) constitute a conceptual triad that may allow us to better understand how partnership function leads to better research outcomes.

\section{Purpose of conducting the scoping review}

Although existing literature discuss trust and $C B P R$ [17], or trust and social networks [18], preliminary searches revealed that none of the literature explores all three concepts of trust, CBPR, and social networks. Furthermore, preliminary searches revealed a lack of consensus regarding how trust is conceptualised, operationalised, and measured. With this in mind, the objectives of this scoping review were to:

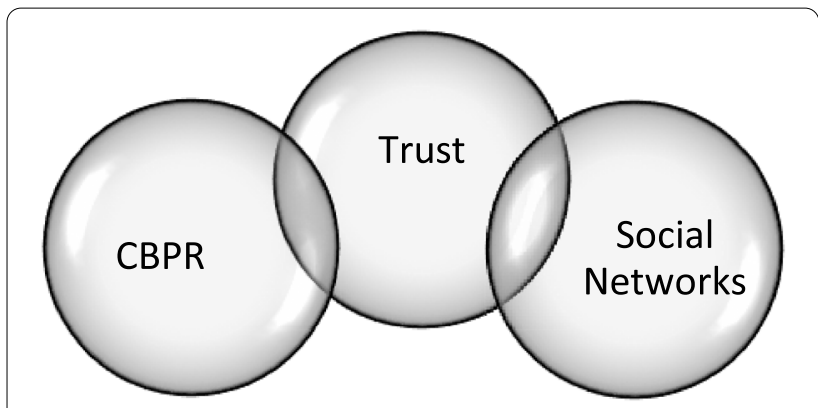

Fig. 1 Trust, CBPR, and social networks as a conceptual triad
1. Identify the literature on trust in CBPR and social networks

2. Clarify how trust is conceptualised, operationalised, and measured in CBPR and social networks

3. Identify where these dimensions of trust may intersect across both CBPR and social networks

Table 1 presents the definitions and boundaries that guided how we conceptualised, operationalised, and measured trust in our scoping review.

\section{Review question}

To clearly identify our research question guiding the scope of the review, we iteratively searched and revised our search terms to capture the most appropriate body of literature. When forming the research question, we identified our main concept of trust and two principal contextual settings for which the concept was explored: CBPR and social networks. The broad nature of these concepts was important in capturing a breadth of literature [19]. This is followed by addressing our target population, being all human studies. Finally, our outcome of interest was to use the literature to see how social network research and CBPR intersect in their conceptualisation, operationalisation, and methods of measurement for trust. This led to the formulation of our research question:

How does the literature conceptualise, operationalise, and measure trust within the context of community-based participatory health research and social networks?

\section{Eligibility criteria}

Deliberation among two additional members of the research team regarding exclusion and inclusion criteria at the outset of the scoping review process occurred. Table 2 provides an overview of the eligibility criteria for this scoping review.

Table 1 Boundaries and definitions for the conceptualising, operationalising, and measurement of trust in our scoping review

\begin{tabular}{|c|c|c|}
\hline $\begin{array}{l}\text { Dimension of our } \\
\text { research question }\end{array}$ & $\begin{array}{l}\text { The definition we attached to this dimension of our } \\
\text { research question }\end{array}$ & $\begin{array}{l}\text { The boundary for data extraction to inform understanding } \\
\text { of the research question dimension }\end{array}$ \\
\hline Conceptualisation & Assigning meaning to something & Definition of trust \\
\hline Operationalisation & $\begin{array}{l}\text { Selecting observable phenomena to represent abstract con- } \\
\text { cepts } \\
\text { How will we go about empirically testing the concept? }\end{array}$ & $\begin{array}{l}\text { Dimensions and indicators of trust } \\
\text { What are the operationalisation issues with the concept? } \\
\text { - Based on our indicators, what questions were asked to } \\
\text { represent trust, what observations were made, what specific } \\
\text { attributes will exist for the measure used? }\end{array}$ \\
\hline Measurement & $\begin{array}{l}\text { Process of observing and recording the observations, or assign- } \\
\text { ing numbers to a phenomenon }\end{array}$ & $\begin{array}{l}\text { Level of measurement such as nominal, ordinal, interval or } \\
\text { ratio and type of measures such as survey, scaling, qualitative, } \\
\text { unobtrusive used for trust }\end{array}$ \\
\hline
\end{tabular}




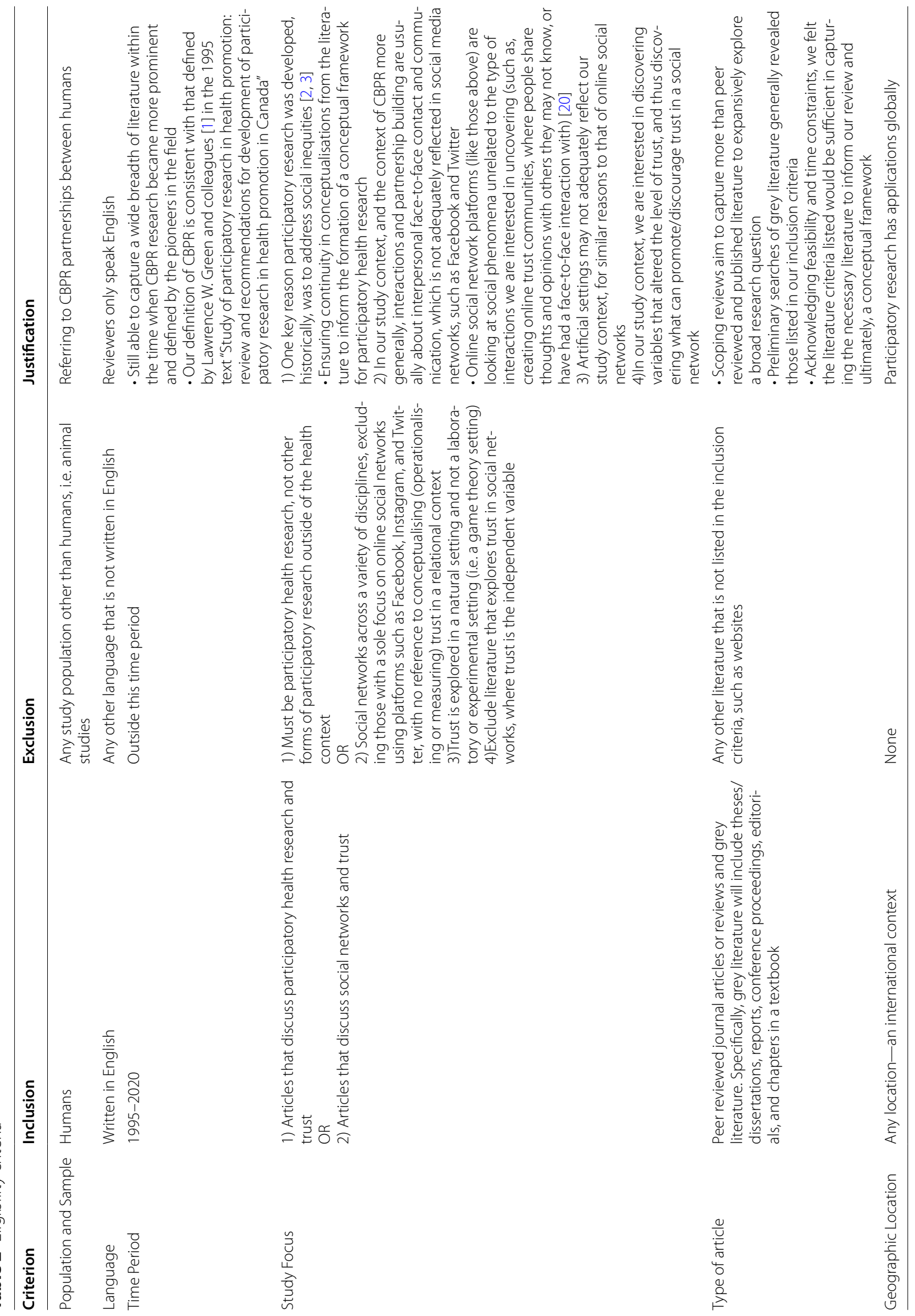




\section{Methods}

This scoping review follows the guidance and framework of Peters et al. [21], which is underpinned by the widely used framework of Levac and colleagues [22]. Levac and colleagues provided enhancements to the methodological framework of Arksey and O'Malley [23]. A published protocol is available for this scoping review [24].

\section{Search strategy}

As initially discussed by Arksey and O'Malley [23], it was important for us to clearly define the terminology we used when conducting the literature search as it ensured the syntax used appropriately captured the literature that best reflected our research question and objectives. Identifying our search strategy was an iterative process that, as proposed by Levac et al. [22], was a team approach. In alignment with the guidelines from Peters et al. [21], a three-step process was used to identify the search strategy.

First, we conducted a preliminary search in CINAHL and Medline searching article titles, abstracts, keywords, and subject headings to guide the development of our search strategy. Secondly, we included the identified keywords and subject headings from the search strategy across all databases being used. Finally, we looked at the reference lists from articles selected for the review. A faculty librarian also provided suggestions and verifications regarding the appropriate syntax and the adaptation of search strategies across databases.

Our final search strategy involved a combination of the three overarching concepts, including concept 1: community-based participatory health research, concept 2 : trust, and concept 3: social networks. Literature needed to include either CBPR (concept one) and trust (concept two) in the title or abstract OR social networks (concept three) and trust (concept two) in the title or abstract:

[(("action research OR community-based participatory research $O R$ public and patient involvement) OR (participatory health research" AND "trust or trusting or trustworthiness or trustworthy")), OR (("social network or social networks") AND ("trust or trusting or trustworthiness or trustworthy"))]

This strategy was used across all databases, with slight refinements to match each of the database requirements. The above search string was used in CINAHL.

Recognizing that comprehensiveness is a key strength of a scoping review, we wanted to ensure data sources were heterogeneous, while not compromising feasibility. With that in mind, we explored several electronic databases including Scopus, Medline, PubMed, Web of Science, CINAHL, Cochrane Library, Google Scholar, and PsychINFO. We also included grey literature such as theses/dissertations and reports. We did not require a separate database to capture additional grey literature, as we felt it was adequately captured in Google Scholar and CINAHL. A complete search strategy from one of the major databases used (CINAHL) is outlined in Additional File 1.

\section{Source of evidence screening and selection}

The resulting literature from each of the aforementioned databases was uploaded to the systematic review software "DistillerSR" (https://www.evidencepartners.com/ products/distillersr-systematic-review-software/). Once duplicates were removed, two independent reviewers screened the articles by title and abstract and then at fulltext based on the pre-determined eligibility criteria, outlined in Table 2.

Noticing the vast amounts of articles to be screened at full-text, more of which involved trust and social networks, we decided that the literature addressing trust in social networks must have included two out of three of our research question components: how trust conceptualised, operationalised, and measured in social networks to be eligible for inclusion. However, for literature addressing PHR and trust, only one of these components needed to be addressed for inclusion. This was considered important to balance the representation of literature from both SN and CBPR in our review.

As anticipated, as the review process progressed, along with our sense of the literature that existed in these areas (trust in CBPR and/or trust in social networks), further changes to the existing eligibility criteria occurred to refine our scope. First, we were interested in exploring trust in social networks as it occurs naturally in relationships. Therefore, studies that included artificial settings, such as experiments that explored "game theory" as a method of exploring trust, were excluded. Second, given the abundance of literature deemed eligible for trust and social networks based on our eligibility criteria, we added additional criteria to further refine our selection for literature about these concepts. Specifically, we discovered that the more suitable literature involved studies that explored trust as a dependent variable as we wanted to see the effect that other variables had on trust and thus how the strength or level of trust was altered when the independent variable was manipulated. Thus, if trust was the independent variable in the literature being reviewed, it was deemed ineligible and excluded. Finally, after the full-text review was completed, we still found we had an over-abundance of items that matched our inclusion criteria. This created the opportunity to be more selective and only retain items that more closely addressed our research question. Thus, we created an additional 
full-text review stage that only included literature that addressed all three of the components from our research question (how trust was conceptualised, operationalised, and measured) for trust in social networks and two of the three components for trust in PHR.

The pair of reviewers met at multiple stages throughout the reviewing process to discuss any discrepancies and changes in eligibility criteria that emerged. Any existing discrepancies regarding which articles to include or exclude and/or why were deemed a "conflict" and subsequently sent to a third independent reviewer who made the final decision. See Fig. 2 below for the PRISMA [25] flow diagram which includes the finalised numbers of what was included and excluded at each stage of the review process.

\section{Data extraction}

To ensure that the most suitable information was extracted, a tabular chart organised in Excel, following guidelines from Peters et al. [21], was incorporated and adapted to include an additional column pertaining to associated questions guiding the charting elements, as illustrated in the protocol by Nittas et al. [26]. Furthermore, additional rows were added that discussed in which context the article was addressing trust, as well as how trust was conceptualised, operationalised, and measured in these contexts. This additional information was important to note for the subsequent stage of the review process; collating, summarizing, and reporting the results (identifying themes). One reviewer completed the data charting process, which was an iterative process as new data was presented in the examination stages, leading to continual charting updates.

\section{Analysis and presentation of results}

As suggested by Peters et al. [21], a narrative summary was included to complement the tabular results and

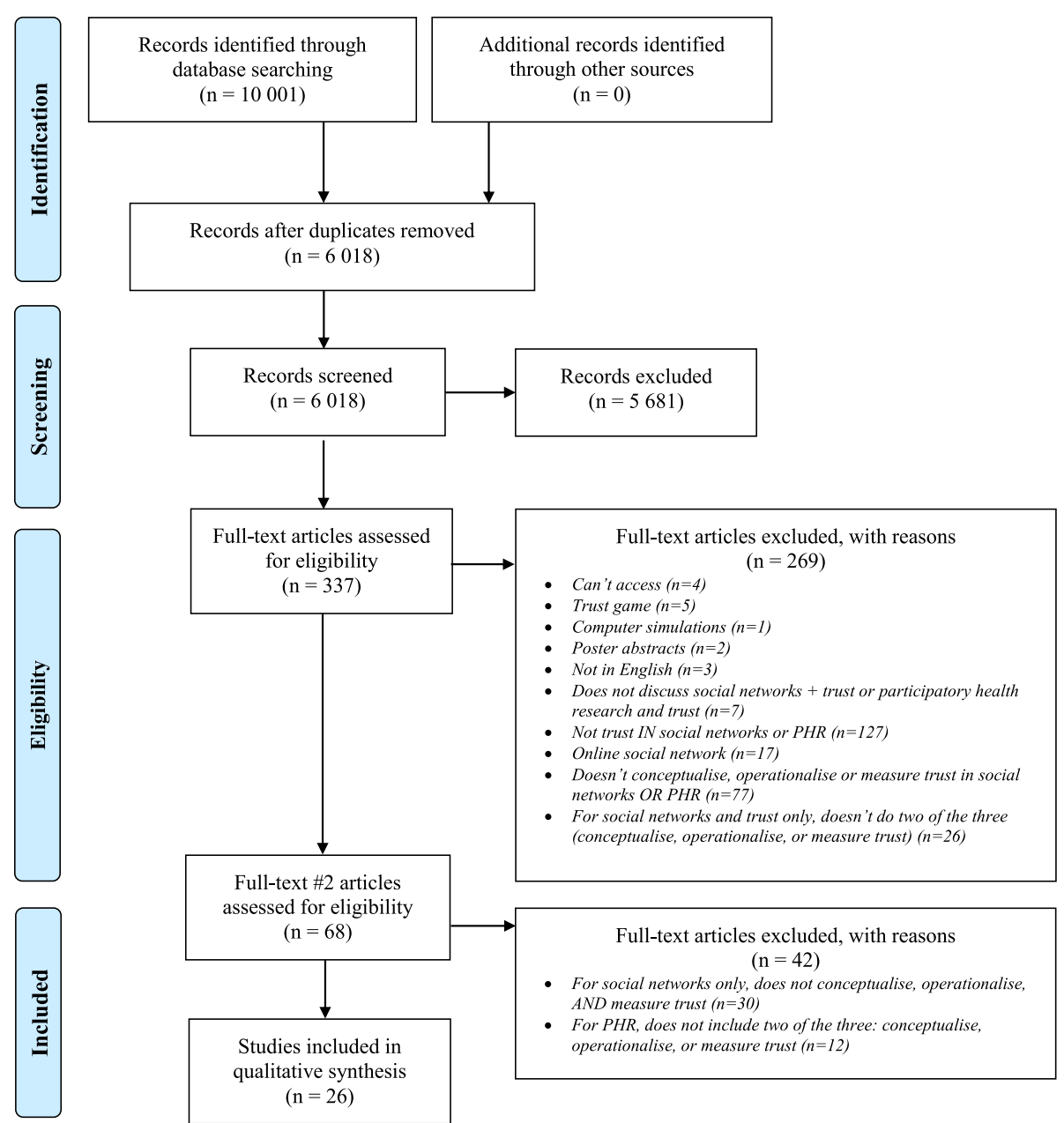

Fig. 2 PRISMA 2009 flow diagram. From: Moher D, Liberati A, Tetzlaff J, Altman DG, The PRISMA Group (2009). Preferred Reporting Items for Systematic Reviews and Meta-Analyses: The PRISMA Statement. PLoS Med 6(7): e1000097. https://doi.org/10.1371/journal.pmed1000097. For more information, visit www.prisma-statement.org 
discuss how the findings relate to the research question and objectives. In addition to this descriptive narrative summary, we also conducted a thematic analysis of the literature using qualitative description [27]. The thematic analysis followed the guidance of Braun and Clarke $[28,29]$. We understood the importance of not pre-empting the findings of the scoping review therefore employed strategies from Braun and Clarke [28, 29] such as "A 15-point checklist of criteria for good thematic analysis" $[28,29]$ to ensure rigour in collating and summarizing the results. NVIVO software was used to analyse extracted data into themes and subthemes which are further explored in the results section of this review. Findings were organised into thematic categories including methodological design and key findings, but also by categories that specifically highlighted the theoretical and operational linkages such as context, conceptual and operational features, and measurements used.

\section{Consultation with knowledge users}

As initially suggested by Levac et al. [22], and later underscored by Peters et al. [21], we recognised that consultation with knowledge users adds to the methodological rigour of a study and should be included as a non-optional stage in developing a scoping review. This review is part of a larger participatory health research project involving 11 collaborating stakeholders that are representatives from community and patient organisations, as well as academic and health services entities that comprise the public and patient involvement capacity building team at the University of Limerick (known as "PPI-Ignite@UL"). There was consultation with them regarding whether or not to conduct the review and if the topic seemed novel and applicable within the scope of the larger study. Indeed, results from this scoping review will be returned to these stakeholders, where feedback will be provided, which will then feed into a larger study based on results from this scoping review.

\section{Results}

\section{Search results}

The search strategy used generated a total of 10001 references. Once these were screened for duplicates, a total of 6018 references were eligible to be screened by title and abstract. When screening by title and abstract, 5681 references were removed as they did not meet our eligibility criteria described in Table 2 . This left 337 articles to be screened at full text. A total of 269 articles were excluded after being reviewed at full text. The predominant reason for exclusion was that trust was not being discussed in social networks or not explored within the CBPR partnerships (i.e. two concepts explored in parallel and not together) $(n=127,47 \%)$. The second highest reason for exclusion was that the article did not conceptualise, operationalise or measure trust in social networks or CBPR ( $n=77,29 \%)$. The remaining reasons for exclusion can be found in Fig. 2 PRISMA 2009 Flow Diagram and the PRISMA-ScR checklist can be found in Additional File 2. As we still had 68 articles remaining, we further refined our screening criteria to achieve a smaller sample for more in-depth analysis and added an additional full-text review stage. Specifically, as explained earlier in the Methods section, given the overabundance of retained items with a social network and trust focus at this stage, we had the opportunity to further refine our inclusion criteria. Thus, for social network and trust articles, if trust was not conceptualised, operationalised, and measured it was excluded ( $n=30,71 \%)$. Meanwhile, for CBPR-related articles, as there was not an overabundance, if two of three (conceptualisation, operationalisation, or measurement) of trust was not present, it was excluded ( $n=12,29 \%)$. After this final review stage was completed, 26 items remained and were included for data extraction and qualitative synthesis.

\section{Inclusion of sources of evidence}

Objective \#1: Identify the literature on trust in CBPR and social networks

From the included literature $(n=26)$ [30-54], 20 references [30-42, 44-46, 50-53] were peer-reviewed journal articles, four references $[47-49,55]$ were dissertations, one reference [43] was a systematic review, and one reference [54] was a book chapter. The included references were published between 2005 and 2019 [30-54]. The majority of references explored trust in social networks $(n=17)$ [30-35, 38-42, 49-54], while seven references explored trust in CBPR [43-48, 55], and two explored both trust in social networks and CBPR [36, 37]. Further individual study details and characteristics can be found in Additional File 3.

\section{Review of findings}

Objectives \#2 and \#3-How is trust conceptualised, operationalised, and measured in CBPR and social networks? Identify where these dimensions of trust may intersect across both CBPR and social networks.

Findings from the thematic analysis exploring how trust is conceptualised, operationalised, and measured for each extracted reference can be found in Additional File 3. For each reference, there are columns illustrating apriori themes-how trust was conceptualised, operationalised, measured. The outcomes pertaining to trust was an emergent theme. Figure 3 shows the identified parent themes and sub-themes. For example, for the conceptualisation of trust, four parent themes were revealed: C1 "context-specific", C2 "relational", C3 "complex 


\begin{tabular}{|c|c|c|c|c|c|c|c|c|c|}
\hline \multicolumn{6}{|c|}{ A priori themes } & \multicolumn{4}{|c|}{ Emergent themes } \\
\hline \multicolumn{2}{|c|}{ Conceptualisation } & \multicolumn{2}{|c|}{ Operationalisation } & \multicolumn{2}{|c|}{ Measurement } & \multicolumn{4}{|c|}{ Outcomes } \\
\hline \multicolumn{2}{|c|}{ C1 Context specific } & \multicolumn{2}{|c|}{ O1 Context specific } & \multicolumn{2}{|c|}{ M1 Type of measure } & \multicolumn{4}{|c|}{ R1 Context specific } \\
\hline $\begin{array}{l}\text { C1.1 Within } \\
\text { individuals }\end{array}$ & $\begin{array}{l}\text { C1.2 Surrounding } \\
\text { individuals }\end{array}$ & $\begin{array}{l}\text { O1.1 Within } \\
\text { individuals }\end{array}$ & $\begin{array}{l}\text { O1.2 Surrounding } \\
\text { individuals }\end{array}$ & M1.1 Survey & M1.2 Scaling & R1.1 Within individua & & R1.2 Sur & ounding individuals \\
\hline \multicolumn{2}{|c|}{ C2 Relational } & \multicolumn{2}{|c|}{ O2 Relational } & $\begin{array}{l}\text { M1.3 } \\
\text { Qualitative }\end{array}$ & $\begin{array}{l}\text { M1.4 } \\
\text { Unobtrusive }\end{array}$ & \multicolumn{4}{|c|}{ R2 Relational } \\
\hline C2.1 Trustworthiness & C2.2 Vulnerability & O2.1 Trustworthiness & O2.2 Vulnerability & \multicolumn{2}{|c|}{ M2 Level of measure } & \multicolumn{2}{|l|}{ R2.3 Integrity } & \multicolumn{2}{|c|}{ R2.4 Reliability } \\
\hline C2.3 Integrity & C2.4 Reliability & O2.3 Integrity & O2.4 Reliability & M2.1 Nominal & M2.2 Ordinal & \multicolumn{2}{|l|}{ R2.5 Ability } & \multicolumn{2}{|c|}{$\begin{array}{l}\text { R2.6 Strength and quality of } \\
\text { relationship }\end{array}$} \\
\hline C2.5 Ability & $\begin{array}{l}\text { C2.6 Strength and } \\
\text { quality of relationship }\end{array}$ & O2.5 Ability & $\begin{array}{l}\text { O2.6 Strength and } \\
\text { quality of relationship }\end{array}$ & \multirow[t]{13}{*}{$\begin{array}{l}\text { M2.3 Open- } \\
\text { ended } \\
\text { question }\end{array}$} & M2.4 Ratio & \multicolumn{2}{|c|}{ R2.7 Shared values, vision, and goals } & \multicolumn{2}{|c|}{$\begin{array}{l}\text { R2.8 Power sharing and co- } \\
\text { ownership }\end{array}$} \\
\hline $\begin{array}{l}\text { C2.7 Shared values, } \\
\text { vision, and goals }\end{array}$ & $\begin{array}{l}\text { C2.8 Power sharing } \\
\text { and co-ownership }\end{array}$ & $\begin{array}{l}\text { C2.7 Shared values, } \\
\text { vision, and goals }\end{array}$ & $\begin{array}{l}\text { C2.8 Power sharing } \\
\text { and co-ownership }\end{array}$ & & & \multicolumn{2}{|l|}{ R2.9 Problem solving } & \multicolumn{2}{|c|}{$\begin{array}{l}\text { R2.10 Power sharing and co- } \\
\text { ownership }\end{array}$} \\
\hline \multicolumn{2}{|c|}{ C3 Complex concept } & \multicolumn{2}{|c|}{ O3 Complex concept } & & & \multicolumn{2}{|l|}{ R2.11 Sustainability } & $\mathrm{R} 2.12 \mathrm{Vu}$ & nerability \\
\hline $\begin{array}{l}\text { C3.1 Multiplicities of } \\
\text { trust }\end{array}$ & $\begin{array}{l}\text { C3.2 Multidimensions } \\
\text { of trust }\end{array}$ & O3.1 Multiplicities of $t$ & & & & & R3 Compl & concept & \\
\hline C4 Features of so & ial network analysis & O4 Features of soc & 1 network analysis & & & & R3.1 Multipli & ties of trust & \\
\hline C4.1 Reciprocal trust & C4.2 Asymmetry & O4.1 Reciprocal trust & O4.2 Homophily & & & R4 F & tures of soci & I network & nalysis \\
\hline & & O4.3 Structural & O4.4 Network & & & & R4.1 Indiv & lual level & \\
\hline & & equivalence & closure & & & R4.1.1 Constraint & R4.1.2 Recil & ocal trust & R4.1.3 Asymmetry \\
\hline & & O4.5 Transf & bility & & & & $\mathrm{R} 4.2 \mathrm{GrC}$ & p level & \\
\hline & & & & & & R4.2.1 Cliques & $\begin{array}{l}\text { R4.2.2 Struc } \\
\text { equivalence }\end{array}$ & & $\begin{array}{l}\text { R4.2.3 Third party } \\
\text { relationships }\end{array}$ \\
\hline & & & & & & & R4.3 Netv & ork level & \\
\hline & & & & & & R4.3.1 Network size & R4.3.2 Struc & ural holes & R4.3.3 Closure \\
\hline & & & & & & R4.3.4 Homophily & R4.3.5 Dens & & R4.3.6 Centralisation \\
\hline
\end{tabular}

concept", and C4 "features of social network analysis." Subsequently, sub-themes attached to each parent-theme were identified. This format of parent-themes and subthemes is similar for operationalisation, measurement, and outcomes pertaining to trust.

\section{Trust: Conceptualised}

When observing the themes and sub-themes presented in Fig. 3, we begin to see the complexities of trust, by noting the many features involved when defining trust as a concept (for detailed descriptions of all themes and subthemes for conceptualisation, please refer to Table 3).

\section{Context-specific}

This parent theme explores definitions of trust as a variable concept that is affected by the individuals in a given partnership and network. Indeed, individuals are unique in their disposition to trust, which is influenced by their personality and their experiences of trust, but also by the context surrounding those individuals such as the structural aspects including institutional barriers, norms, and values that surround trust:

First, initial trust depends on personality; people simply differ in their general disposition to trust/dis- trust [32].

trust must be understood from the perspective of all parties and within its context [44]

This notion that trust depends on context was widely discussed across the extracted literature $(n=18)$ [30, 32$35,40,41,43-47,49,51-55]$, from both CBPR and social network focused studies.

\section{Relational}

All studies defined trust as a "relational" concept, involving a dyadic relationship where trust is being given by a trustor and received by a trustee. All but one of the extracted references [33] defined trust by mentioning at least one of the eight "relational" subthemes (see Table 3). This one study by Burt et al. [33] that did not mention one of the eight sub-themes did however discuss trust as a function of relationships, but strictly through a social network analysis lens, without further defining trust in regards to its relational features. Of the eight sub-themes discussed, integrity, reliability, and ability appeared to be closely related and thus were at times conceptually ambiguous across the literature. Therefore, we draw specific attention to their nuances as distinct concepts. 


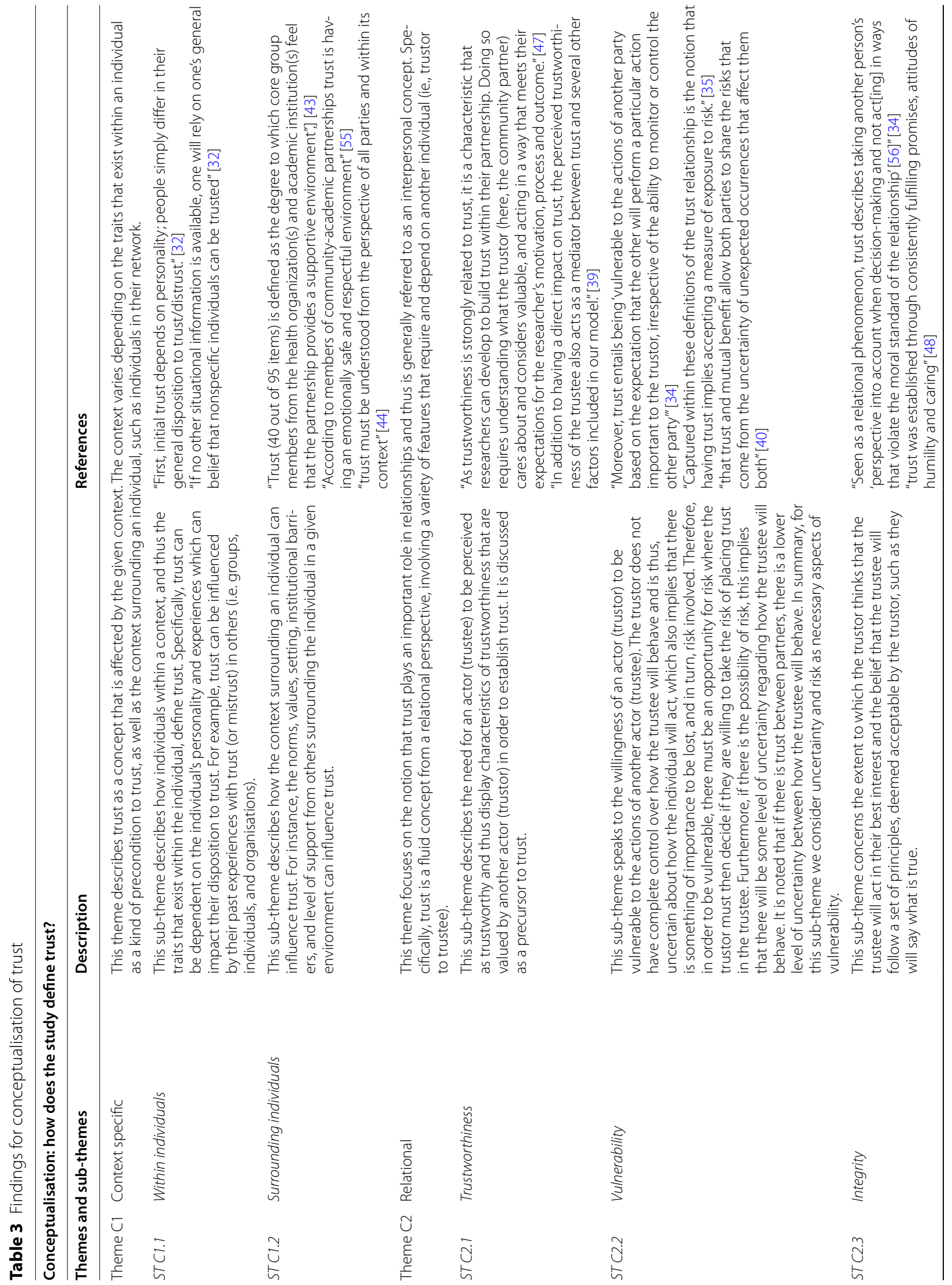




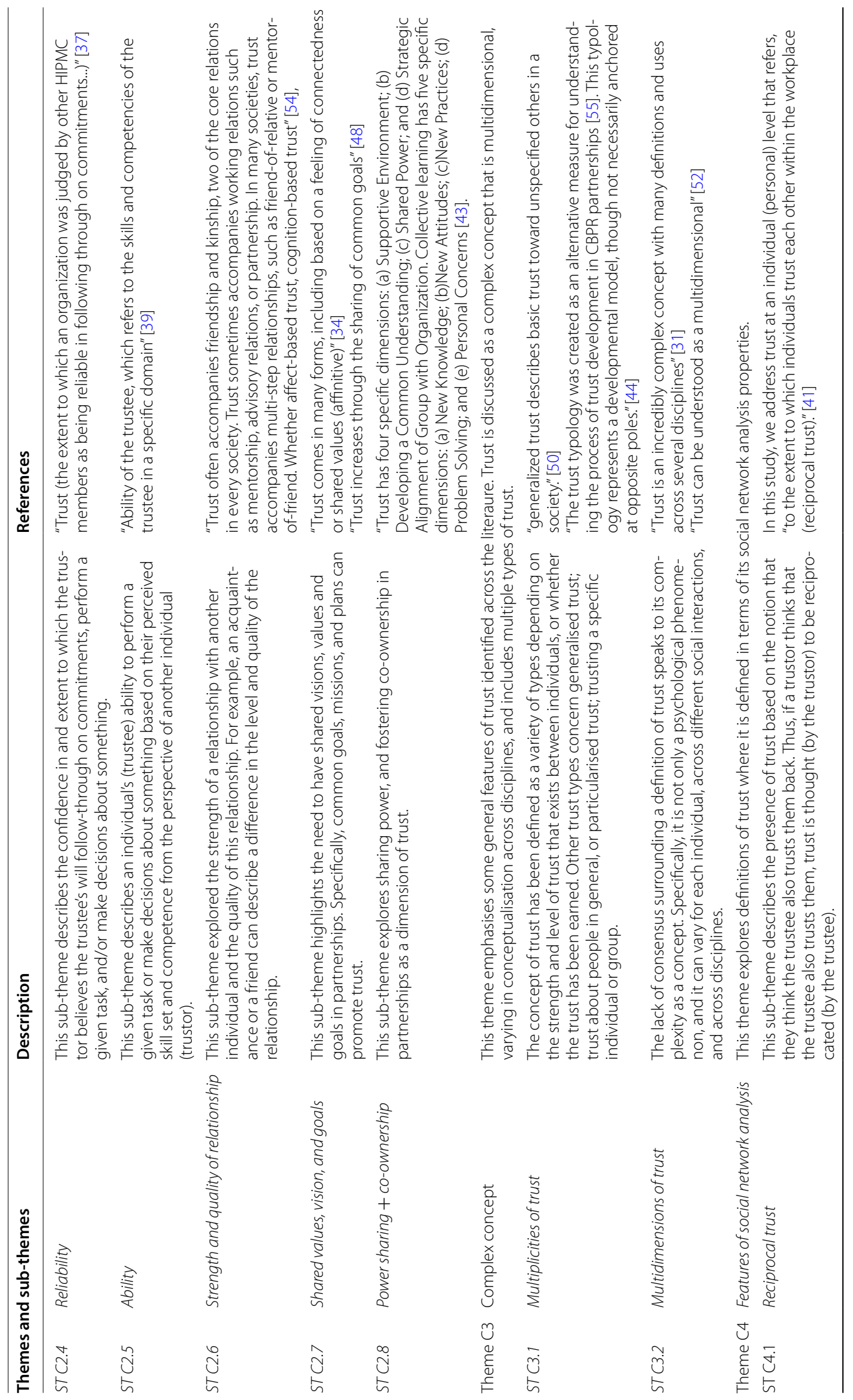




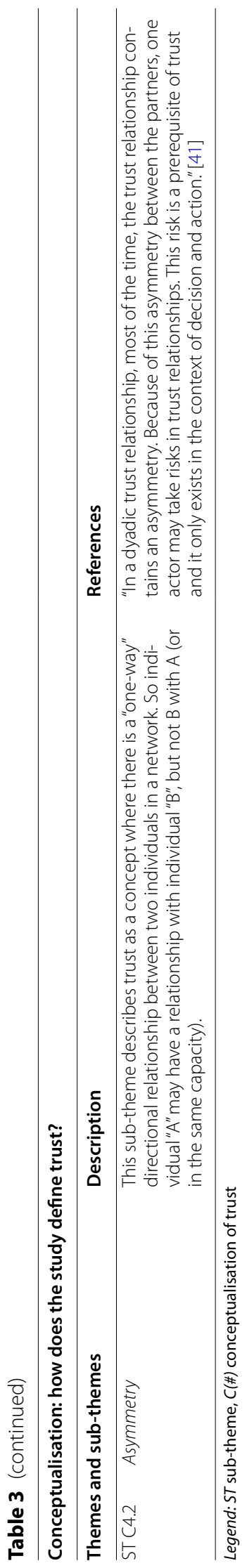


For instance, C2.3 "integrity" speaks to the actions of an individual from a moral or ethical perspective, such as whether or not the individual will act in the best interest of another individual:

Seen as a relational phenomenon, trust describes taking another person's 'perspective into account when decision-making and not act[ing] in ways that violate the moral standard of the relationship' (Weber and Carter 1998, 3) [34].

Meanwhile C2.4 "reliability", embodies some such aspects, but speaks more to the confidence the trustor has that the trustee will follow through on a commitment or perform a given task:

Trust (the extent to which an organization was judged by other HIPMC members as being reliable in following through on commitments...) [37]

Lastly, although C2.5 "ability" can also influence whether or not an individual performs a given task or is reliable, it speaks more to the perceived skillset and thus competence that the trustor feels the trustee has:

Ability of the trustee, which refers to the skills and competencies of the trustee in a specific domain [39]

Finally, there were two differences identified when exploring the presence of certain sub-themes for conceptualisation across CBPR and social network studies. Indeed, the sub-theme $\mathrm{C} 2.6$ "strength and quality of relationship" was only identified in social network studies $[30,41,52,54]$, while C2.8 "power sharing and co-ownership" was only recognized in CBPR studies [43, 45, 47].

\section{Complex concept}

As demonstrated by the three relational sub-themes discussed above (integrity, reliability, and ability), trust embodies distinct concepts within itself that could be conceptualised differently across the literature and thus, further explored and unpacked. Indeed, our third parent theme speaks to just this: trust as a complex concept. Specifically, trust was defined as a multiplicity of types that varied depending on strength and level, and/or who the trust was directed at, such as a general or particular population:

generalized trust describes basic trust toward unspecified others in a society [51].

The trust typology was created as an alternative measure for understanding the process of trust development in CBPR partnerships [55]. This typology represents a developmental model, though not necessarily anchored at opposite poles [45].
Trust can also be defined as multidimensional in that it differs across disciplines, social interactions and is not solely a psychological phenomenon. Of the extracted literature, many of the studies $(n=19)[30-33,35,36,38$, $39,41,44,45,47,49-55$ ] defined trust as a complex, multidimensional concept:

Trust is an incredibly complex concept with many definitions and uses across several disciplines [31]

\section{Trust can be understood as a multidimensional [52]}

Both sub-themes C3.1 "multiplicity of trust" and C3.2 "multidimensions of trust" were identified in the references extracted with a social network focus [30-33, 35, $36,38,39,41,49-54]$, as well as those with a CBPR focus $[36,44,45,47,55]$.

\section{Features of social network analysis}

A final theme that was less common, but emerged across three social network studies, was conceptualising trust in regards to specific features of social network analysis [35, $41,53]$. Specifically, the social network analysis features used to define trust speak to the direction of receiving and giving trust, as either bi-directional (reciprocal) or unidirectional (asymmetric). Gursakal et al. [41] defined trust as reciprocal, but then discussed how trust relationships often contain some asymmetry, depending on context:

In this study, we address trust at an individual (personal) level that refers, "to the extent to which individuals trust each other within the workplace (reciprocal trust) [41].

In a dyadic trust relationship, most of the time, the trust relationship contains an asymmetry. Because of this asymmetry between the partners, one actor may take risks in trust relationships. This risk is a prerequisite of trust and it only exists in the context of decision and action [41].

Not surprisingly, only social network focused studies conceptualised trust in terms of their features of social network analysis. Specifically, three studies [35, 41, 53] identified the sub-theme C4.1 "reciprocal trust", while one study [41] discussed C4.2 "asymmetry" in their conceptualisation of trust.

\section{Trust: Operationalised}

The questions and indicators used to operationalise trust were coded into the same four emergent parent themes identified for the conceptualisation of trust (see Fig. 3). The sub-themes for operationalisation describe 
the questions and indicators of trust (for a complete list of themes, sub-themes, and descriptions, please refer to Table 4).

\section{Context specific}

There are two sub-themes (O1.1 "within individuals" and O1.2 "surrounding individuals") attached to the parent theme $\mathrm{O} 1$ "context-specific". "Within individuals" describes the questions and indicators that explore how individuals within a context can impact trust, such as an individual's unique disposition to trust:

\section{a. Talk to me about how you view trust within the POPS-CAB. I'm interested in hearing your views on benefits/opportunities as well as the challenges/bar- riers related to trust [46].}

Meanwhile, "surrounding individuals", looks at questions and indicators that explore trust based on those surrounding the individual in a specific environment or network:

The trust network was measured by asking participants with respect to their particular team "Who do you trust? [50]

Both sub-themes were identified in social network [30, 34-36, 39, 42, 49-53] and CBPR [36, 43-48, 55] focused literature.

\section{Relational}

All of the eight sub-themes for the parent theme $\mathrm{O} 2$ "relational" mirrored that of how trust was conceptualised. For example, it is possible to identify the nuances between some relational sub-themes that were discussed earlier as conceptually ambiguous, such as: O2.3 "integrity", O2.4 "reliability", and O2.5 "ability", by looking at the specific questions and indicators used to operationalise trust for each of these sub-themes. For example, O2.3 "integrity" was represented by questions and indicators that explore the extent to which a trustor thinks the trustor will act in their best interest:

Please indicate those who you think will act in your best interests [39]

While O2.4 "reliability", speaks to the confidence that the trustor has in the trustee following through on commitments:

Most of my workmates can be relied upon to do as they say they will do [53]

And O2.5 "ability" captures questions and indicators that explore the trustee's skillset from the perspective of the trustor:

\section{I feel confident about my co-workers' skills [41]}

Two differences were observed when looking at the presence of sub-themes across social network and CBPR focused literature. Specifically, only social network-focused studies appeared to operationalise trust as O2.2 "vulnerability" [32, 34, 41]. However, a CBPR focused study by West K [47], did operationalise vulnerability in regards to trustworthiness, but not as trust specifically. Furthermore, similar to conceptualisation, two CBPR focused references [43, 44] operationalised trust as $\mathrm{O} 2.8$ "power sharing and co-ownership".

\section{Complex concept}

For this parent-theme O3 "complex concept", we noticed that one of the sub-themes discussed in conceptualisation, "multidimensions of trust", was not captured in how trust was operationalised throughout the extracted literature. Specifically, there was only the one sub-theme, O3.1 "multiplicities of trust" identified. The "multiplicities of trust" represent questions and indicators that address specific types of trust:

Survey participants were asked to select the trust type they experienced at the beginning of their partnership and the type they currently experience [55].

Multiplicities of trust was identified in both social network $[41,51]$ and CBPR $[45,55]$ studies.

\section{Features of social network analysis}

This parent theme is where we see most of the variation in sub-themes compared to how trust was conceptualised. Moreover, the only consistent sub-theme across how trust was conceptualised and operationalised is $\mathrm{O} 4.1$ "reciprocal trust":

\section{SNA questionnaire for personal trust at intra organ- isational level measures personal trust levels of the co-workers to each other (reciprocal trust) [41].}

Meanwhile, four new sub-themes were presented for how trust was operationalised: O4.2 "homophily", O4.3 "structural equivalence", O4.4 "network closure", and O4.5 "transferability".

This presence of more features of social network analysis used to operationalise trust compared to conceptualise trust is less surprising given the less abstract and more practical nature of operationalisation.

\section{Trust: Measurement}

How trust was measured across the extracted literature was organized into two main parent themes, M1 


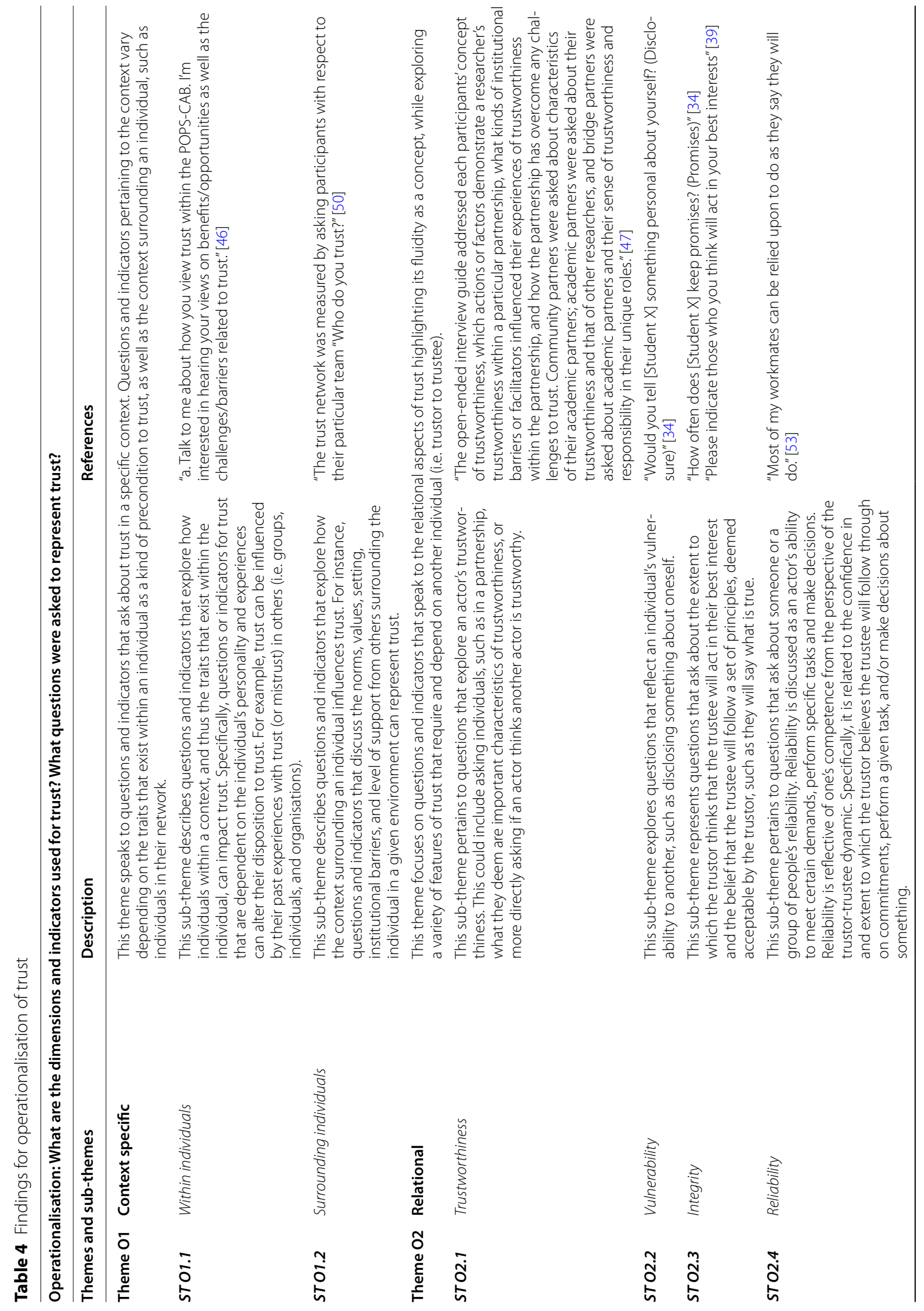




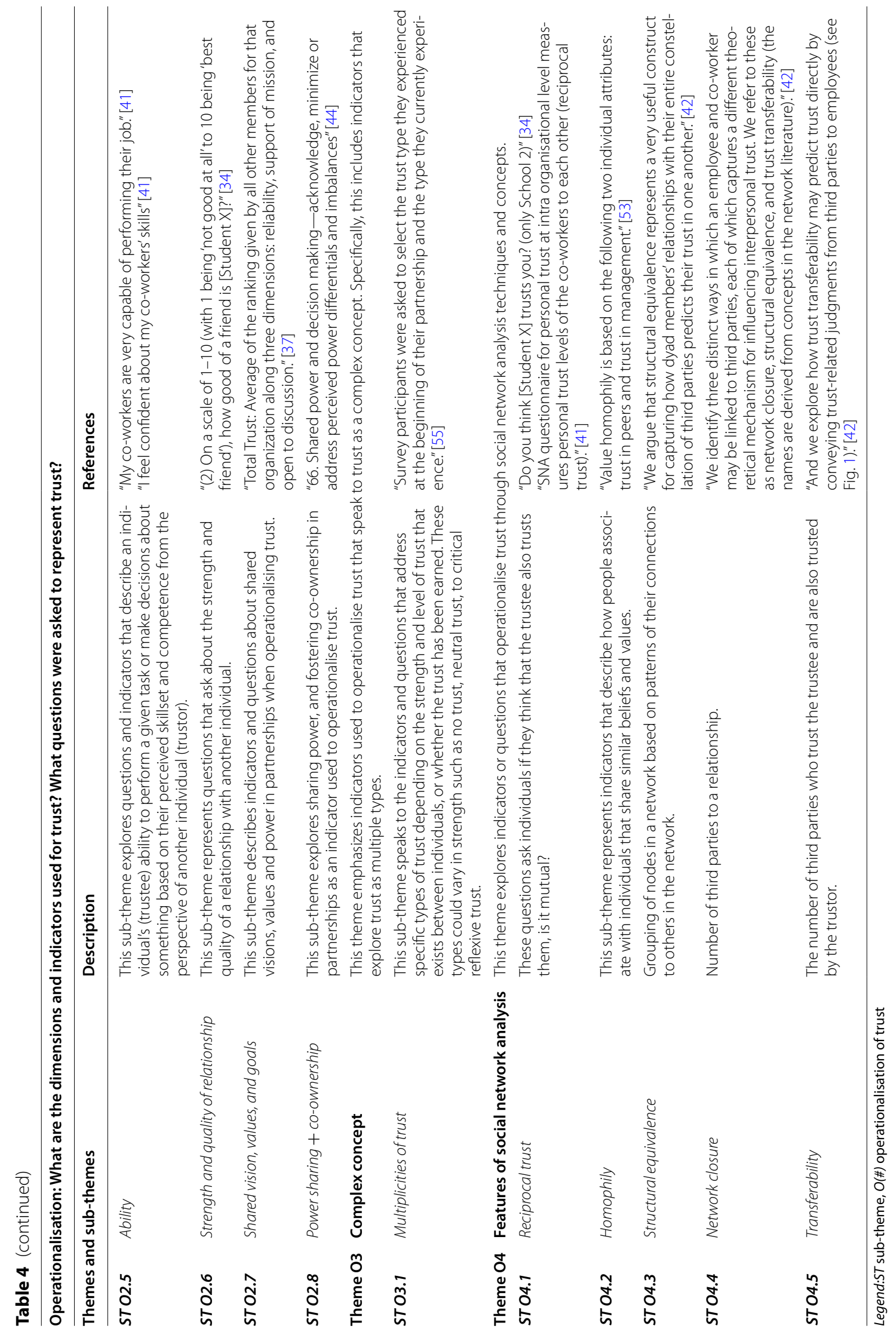


Table 5 Findings for measurement of trust

\begin{tabular}{|c|c|c|c|}
\hline \multicolumn{4}{|c|}{ Measurement: how is trust measured? } \\
\hline \multicolumn{2}{|c|}{ Themes and sub-themes } & Description & References \\
\hline Theme M1 & Type of measure & \multicolumn{2}{|c|}{ What type of measures was (survey, scaling, qualitative, unobtrusive) used for trust? } \\
\hline STM1.1 & Survey & $\begin{array}{l}\text { The type of measurement used to measure trust was } \\
\text { a survey. }\end{array}$ & $\begin{array}{l}\text { "we drew upon previously validated survey instruments } \\
\text { used to measure peer-to-peer trust in classroom set- } \\
\text { tings" [34] } \\
\text { "The web-based survey provided the types of trust with } \\
\text { their definitions" [45] }\end{array}$ \\
\hline STM1.2 & Scaling & A scale was used to measure trust. & $\begin{array}{l}\text { "The respondents were also asked to rate the level of } \\
\text { trust they have that they will be provided with the input } \\
\text { they need from each identified other actor (on a similar } \\
\text { Likert scale from no trust to full trust)" [31] }\end{array}$ \\
\hline STM1.3 & Qualitative & $\begin{array}{l}\text { The type of measurement technique used to measure } \\
\text { trust was qualitative. }\end{array}$ & $\begin{array}{l}\text { "The question of trust often led to open-ended } \\
\text { responses which were recorded and probed on." [36] } \\
\text { "In-depth interviews were conducted between October } \\
2015 \text { and September 2016, by phone }(n=28) \text { and in- } \\
\text { person }(n=3) . \text {." [47] }\end{array}$ \\
\hline ST M1.4 & Unobtrusive & $\begin{array}{l}\text { The type of measurement technique used was unob- } \\
\text { trusive and thus does not require the researcher to } \\
\text { intrude in the research context. }\end{array}$ & $\begin{array}{l}\text { "Observations in the US and especially in Malawi helped } \\
\text { me understand the context and day to day challenges } \\
\text { in Malawi (see Table } 4.4 \text { for a description of observations } \\
\text { in Malawi)." [48] }\end{array}$ \\
\hline Theme M2 & Level of measure & \multicolumn{2}{|c|}{ What level of measurement was used (nominal, ordinal, interval, ratio) to measure trust? } \\
\hline STM2.1 & Nominal & $\begin{array}{l}\text { Items are named, but are in no specific order. The } \\
\text { numbers assigned to it are thus arbitrary. }\end{array}$ & $\begin{array}{l}\text { "TRUST: } 0=\text { Did not select respondent } 1=\text { Selected } \\
\text { respondent" } \\
\text { "Asked participants to select the most appropriate type } \\
\text { of trust at the beginning of their partnership and the } \\
\text { current stage of their partnership and to choose the } \\
\text { type of trust expected in the future." [45] }\end{array}$ \\
\hline STM2.2 & Ordinal & $\begin{array}{l}\text { Items can be ordered, such as level of agreement, of } \\
\text { low to high degrees of trust. }\end{array}$ & $\begin{array}{l}\text { "Scale from 1-4 one being 'poor relationship/little trust' } \\
\text { and four being "excellent relationship/high trust" [35] } \\
\text { "The scale consisted of self-report items scaled in a } \\
\text { five-point Likert scale (1 = completely disagree to } 5= \\
\text { completely agree)." [41] }\end{array}$ \\
\hline STM2.3 & Open-ended question & There was no forced choice for these questions. & $\begin{array}{l}\text { "65. What could be done to improve the trust among } \\
\text { movement members?" [49] }\end{array}$ \\
\hline STM2.4 & Ratio & $\begin{array}{l}\text { Items are named, but are in no specific order. The } \\
\text { numbers assigned to it are thus arbitrary. }\end{array}$ & $\begin{array}{l}\text { "Percentage, A } 100 \% \text { occurs when all members trust } \\
\text { others at the highest level" [37] }\end{array}$ \\
\hline
\end{tabular}

Legend ST sub-theme, $M(\#)$ measurement of trust

"type of measurement" and M2 "level of measurement". Each of the parent themes had four sub-themes: M1.1 "survey", M1.2 "scaling", M1.3 "qualitative", and M1.4 "unobtrusive" and M2.1 "nominal", M2.2 "ordinal", M2.3 "open-ended questions", and M2.4 "ratio" (for a complete list of themes, sub-themes, and descriptions, please refer to Table 5).

\section{Type of measurement}

The type of measurement used across the literature often involved more than one type. This is not surprising given the mixed-method nature of many of the studies [30, 31, 34, 36, 40, 44-49, 51, 52, 55]. All but two of the studies involved the administration of a survey $[44,48]$ and all but one of the studies incorporated scaling questions [43, 48]. MacIntyre et al. [48] did not incorporate scaling questions, but conducted structured interviews and observation. Finally, only one study by Ardoin et al. [33] incorporated all four types of measurement in their study design.

\section{Level of measurement}

The level of measurement was somewhat consistent across studies. For instance, all but five studies [39, 43, 45, $48,50,52]$ incorporated an ordinal level of measurement in their study to measure trust. Six studies [39, 43, 45, 50, 52 , 55] included a nominal level of measurement, and only one study by McCullough et al. [37] incorporated a ratio level of measurement, but also included an ordinal level of measurement in the study. Finally, four studies $[43,44,48,49]$ incorporated open-ended questions. 
When comparing type and level of measurement across social network and CBPR focused literature, no apparent patterns were observed.

\section{Trust: Outcomes}

Studies were also coded by their outcomes, exploring study findings that were identified to be associated with trust in some manner. By coding the outcomes, we could more easily identify patterns across and within studies. Mirroring that of conceptualisation and operationalisation, there were four parent themes identified for the outcomes: R1 "context specific", R2 "relational", R3 "complex concept", and R4 "features of social network analysis".

Comparatively with conceptualisation and operationalisation, the same sub-themes were identified for R1 "context-specific", and similar to operationalisation, there was one sub-theme identified for R3 "complex concept". Interestingly, however, R2 "relational" and R4 "features of social network analysis" saw new sub-themes emerge in the outcomes. For example, for R2 "relational", there were three additional sub-themes identified, while for R4 "features of social network analysis", 11 new sub-themes emerged as outcomes associated with trust (see Fig. 3 for a complete list of sub-themes and Table 6 for a list of parent and sub-theme descriptions).

Similar to conceptualisation and operationalisation, R2 "relational" features of trust continued to be the most common parent theme for outcomes related to trust across studies. Comparatively, the second most prevalent parent theme was, R4 "features of social network analysis", indicating the reporting of more features of social network analysis connected with trust in some way (e.g., associated or indicating trust).

When looking at the differences in sub-themes across social network and CBPR literature, similar to operationalisation, we see the majority of features of social network analysis sub-themes emerging in social network focused literature. However, we did identify one study by Dave et al. [44] which was CBPR focused, that discussed outcomes pertaining to reciprocal trust. Furthermore, a study by McCullough et al. [37] that had both a social network and CBPR focus, discussed centralisation as an outcome from a trust network.

\section{Discussion}

In summary, when exploring all three concepts together (trust, CBPR and social networks), we identified 26 references that met our inclusion criteria, with an overwhelming majority exploring trust in social networks. Following, an iterative and in-depth analysis of this literature occurred, which provided clarification for how trust was conceptualised, operationalised, and measured. Furthermore, our thematic analysis revealed an emergent category that highlighted another important dimension of trust-outcomes pertaining to trust. Interestingly, the same four parent themes; context-specific, relational, complex concept, and features of social network analysis, emerged for how trust was conceptualised, operationalised and outcomes pertaining to trust. This was not consistent for measurement of trust, due to the nature of the category, in that it involved the level and type of measurements used in the literature. Furthermore, no key patterns were shown for how trust was measured based on social network or CBPR focused literature. Indeed, subthemes that emerged were also similar across conceptualisation, operationalisation and outcomes pertaining to trust. The primary differences in how the literature conceptualised and operationalised trust, and the outcomes pertaining to trust can be recognised at a sub-theme level. In general, it seemed that more features of social network analysis emerged when the literature operationalised trust, and even more so when they discussed outcomes of trust. Finally, when exploring the dimensions of trust across CBPR and social network literature, we saw an intersection in many of the themes and subthemes that emerged, while noting only a few differences. For example, for conceptualisation, the sub-theme C2.6 "strength and quality of relationship" was only present in social network-focused literature [30, 41, 52, 54], while C2.8 "power sharing and co-ownership" was only present in CBPR focused literature [43, 45, 47]. As for operationalisation, the sub-theme $\mathrm{O} 2.8$ "vulnerability" was only discussed in social network-focused literature [32, 34, 41], while again, O2.8 "power sharing and co-ownership" was only mentioned in CBPR literature [43, 44].

As the first scoping review exploring all three concepts (trust, CBPR, and social networks) together, this research adds to the existing literature in a few key ways. First, the analysis from this scoping review illuminates the complexities of trust. Second, the analysis highlights the variation within studies in how they conceptualise and operationalise trust, as well as the outcomes of trust. Finally, this research provides important insight into the multidimensionality of which trust operates as a context, mechanism, and outcome.

Recognizing these connections with existing literature, the findings from our scoping review identify important implications for future research. First, by illuminating the complexities of trust, future research in the field of CBPR may be better positioned to strengthen the conceptual rigour and consistency of trust in their own CBPR studies. For example, within most individual studies, trust was operationalised differently than it was conceptualised, even when only looking at parent themes. Specifically, only four studies were coded with the same parent themes for how they conceptualised and operationalised 


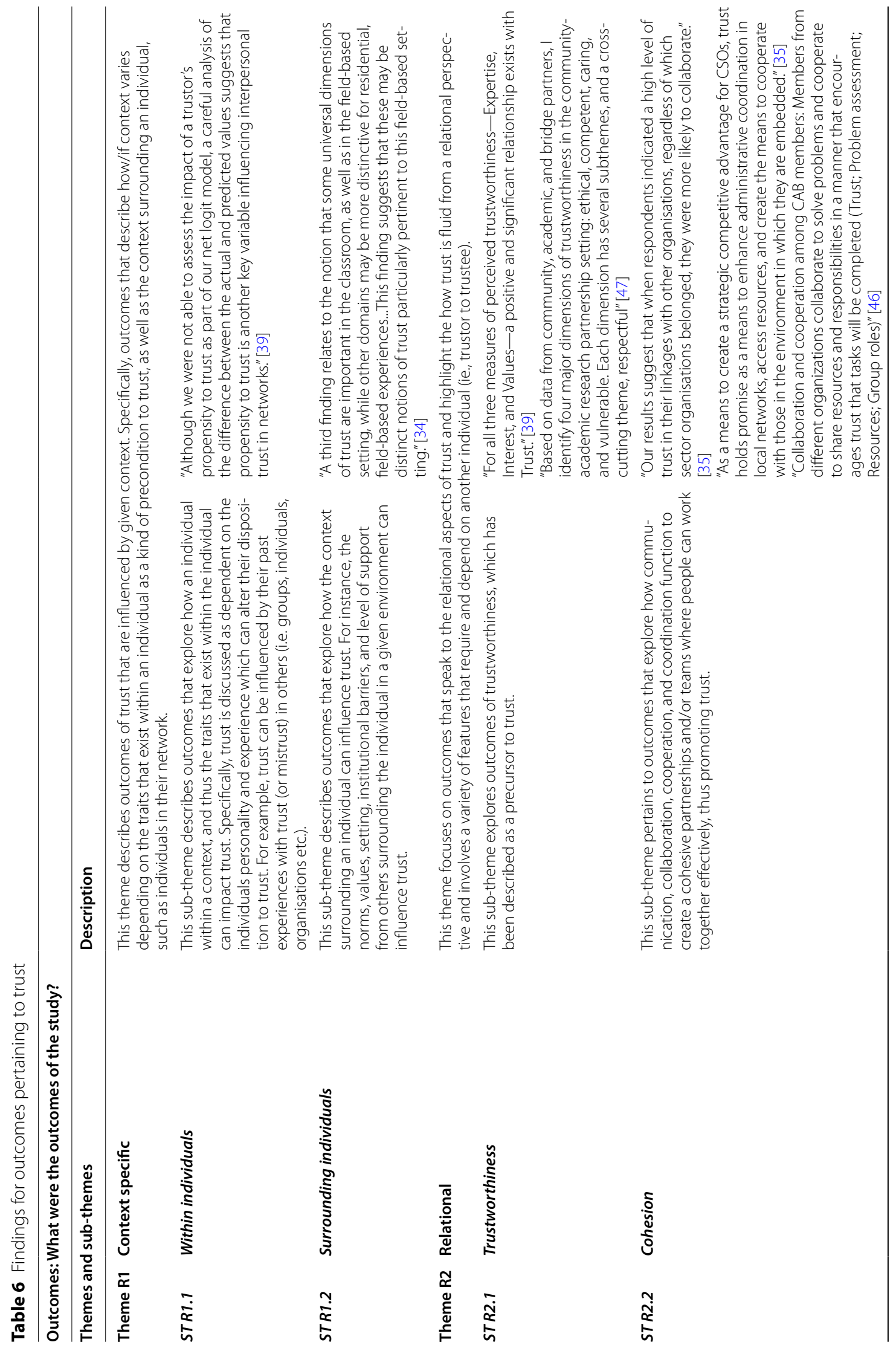




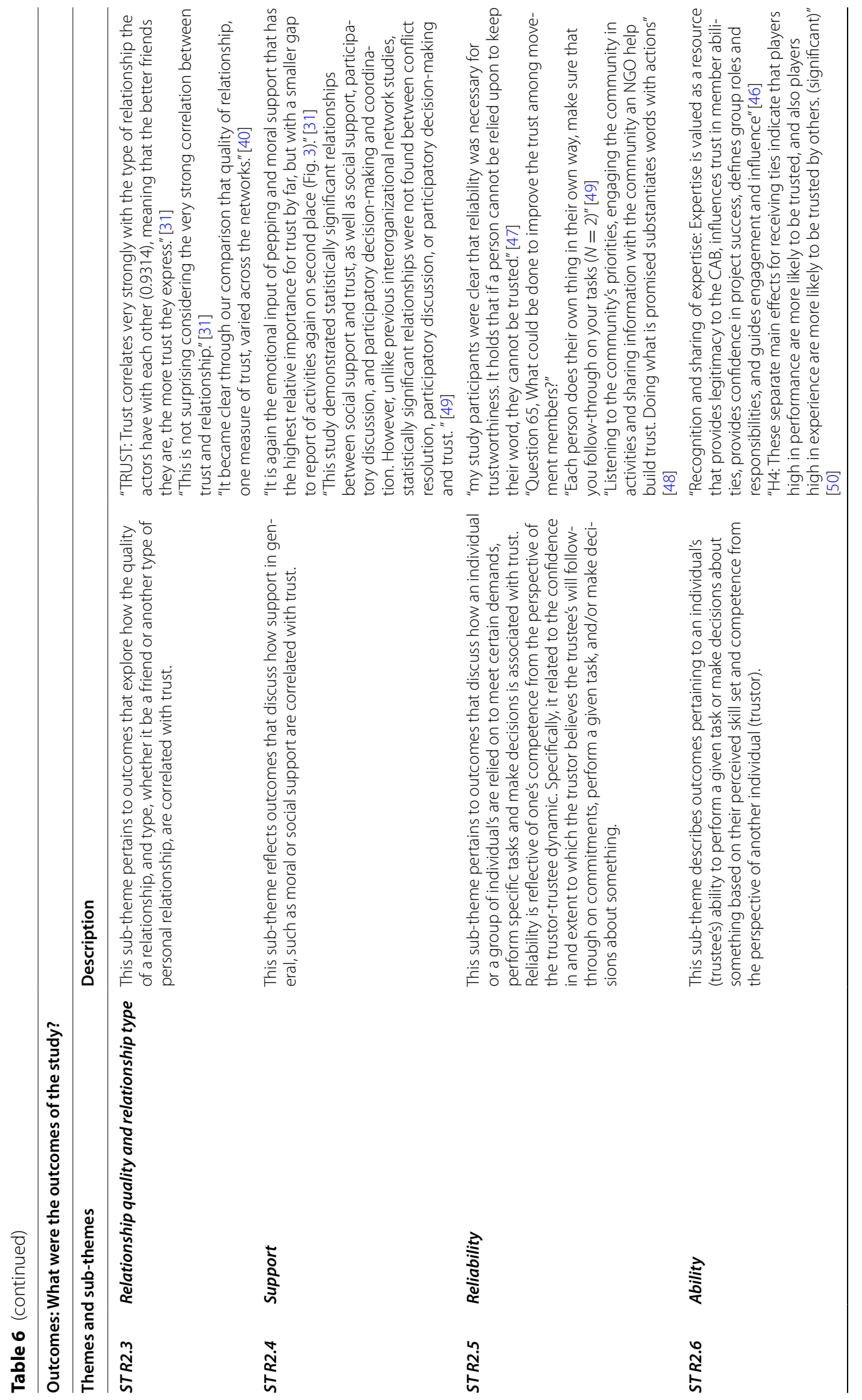




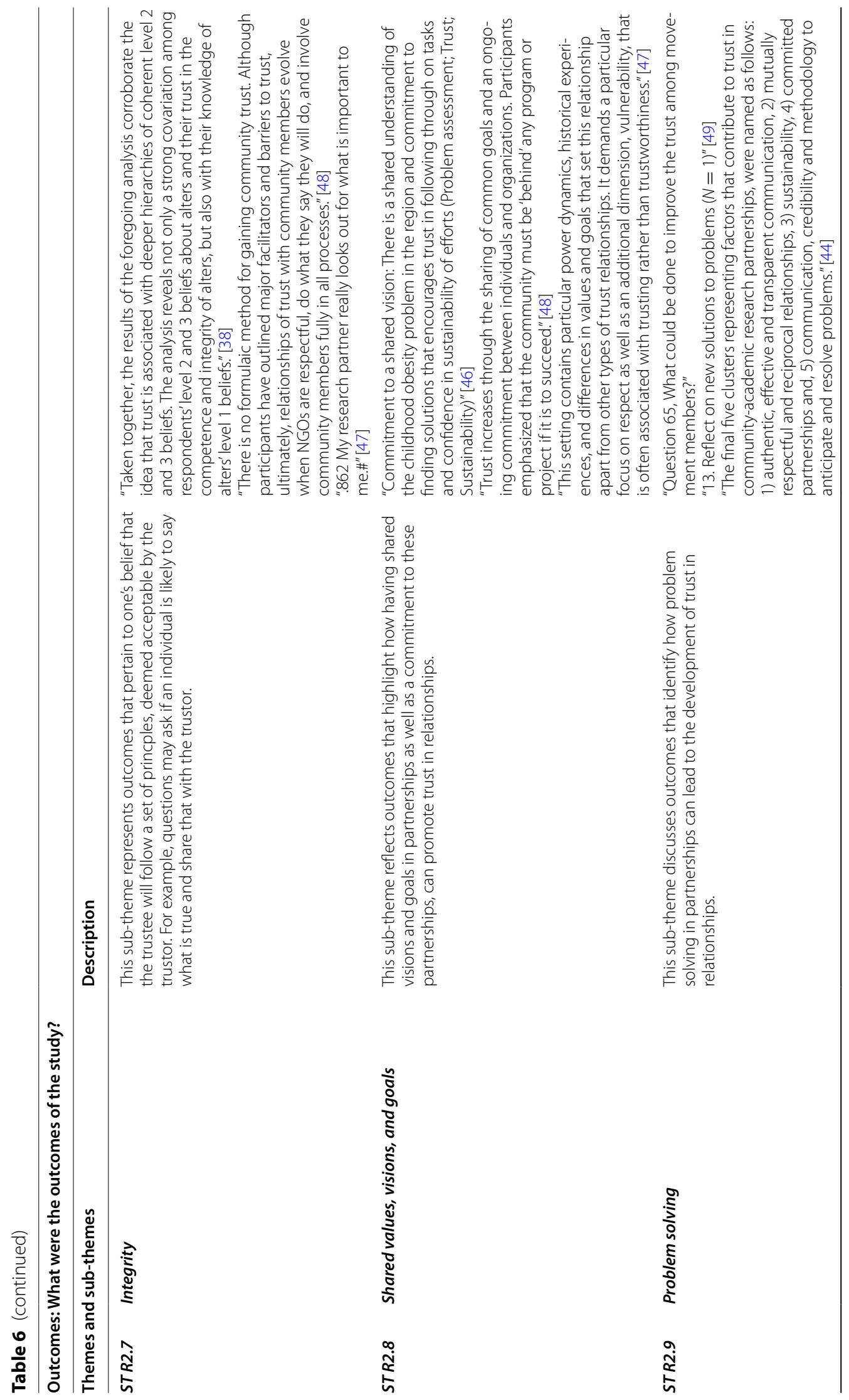




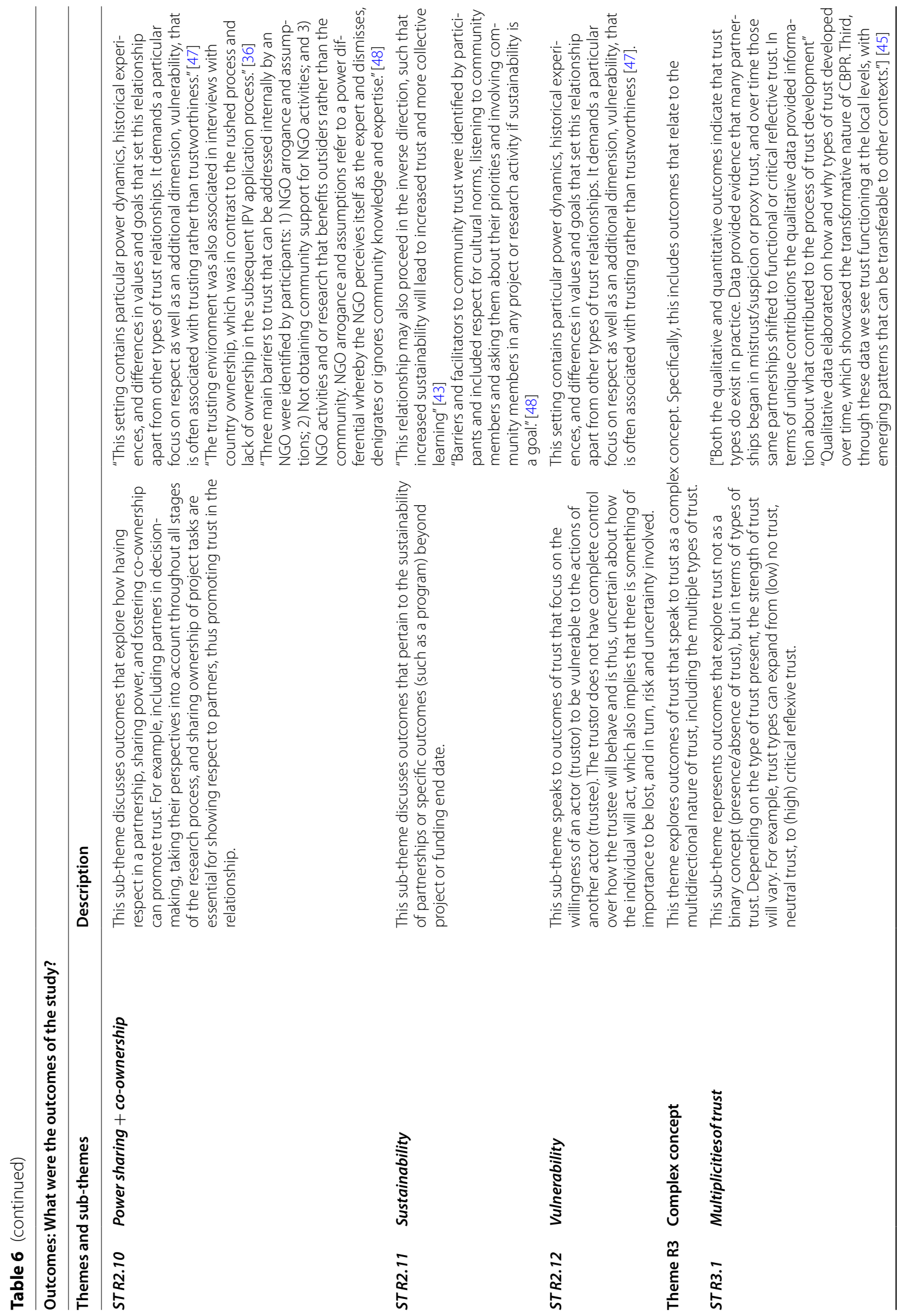




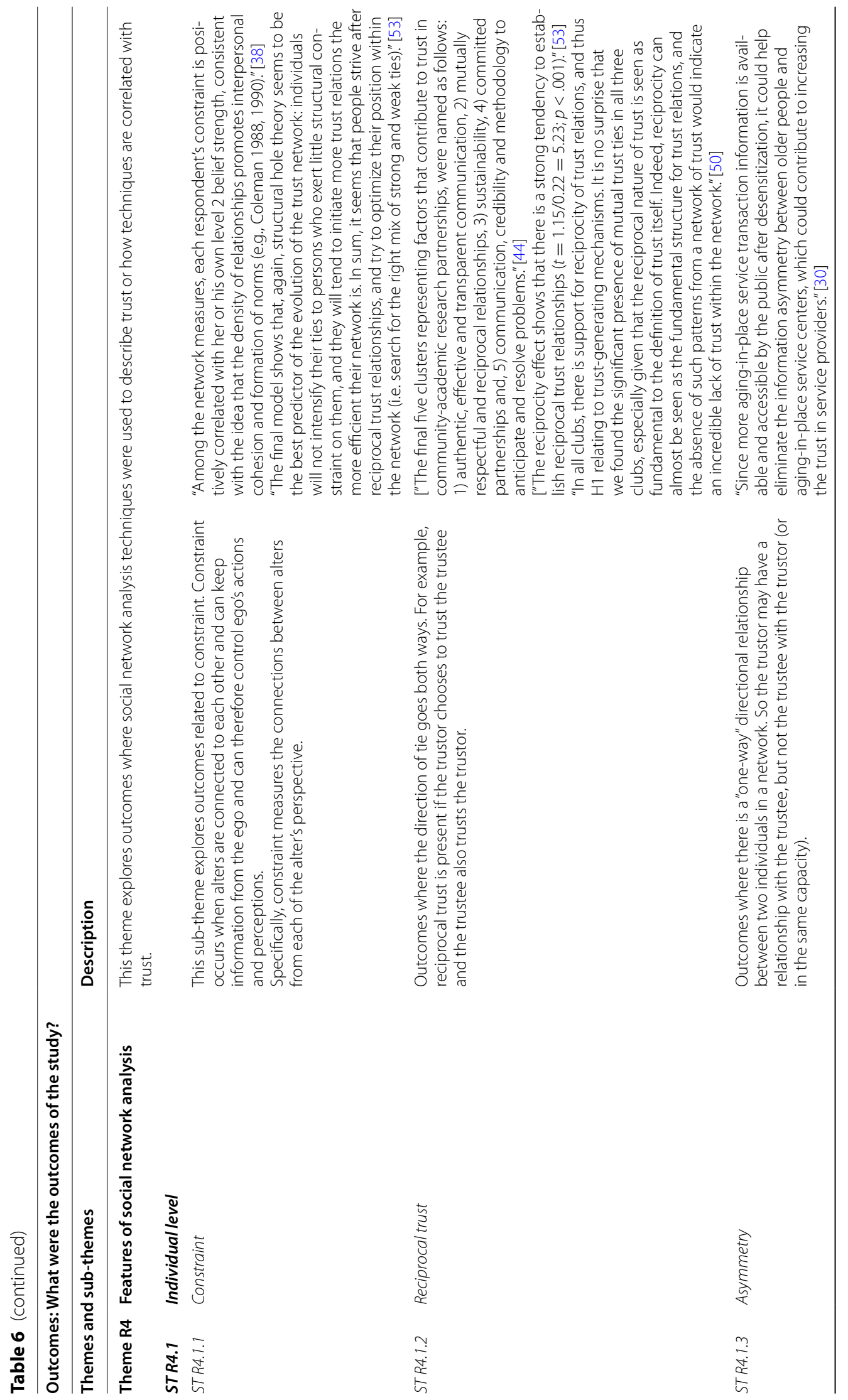




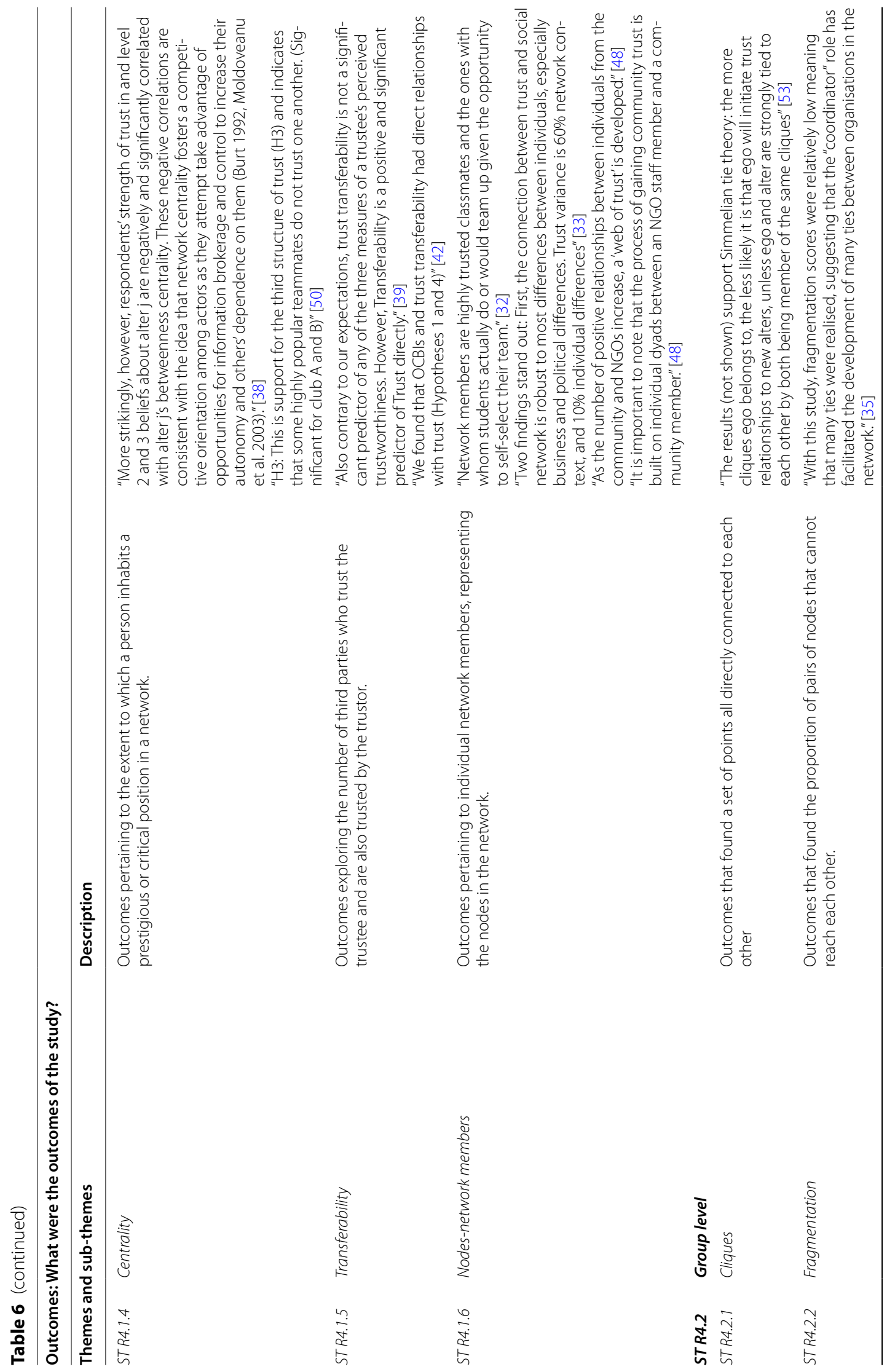




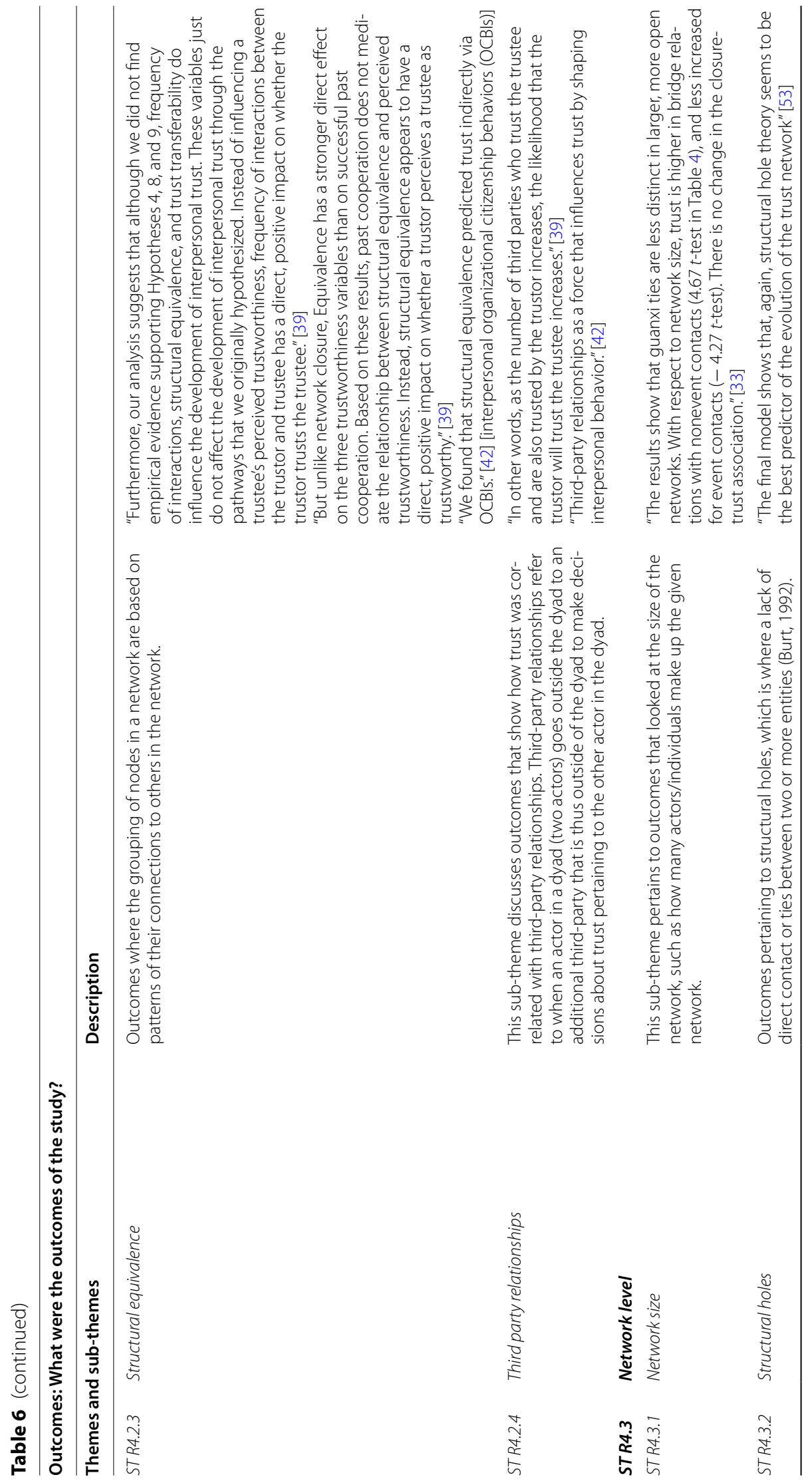




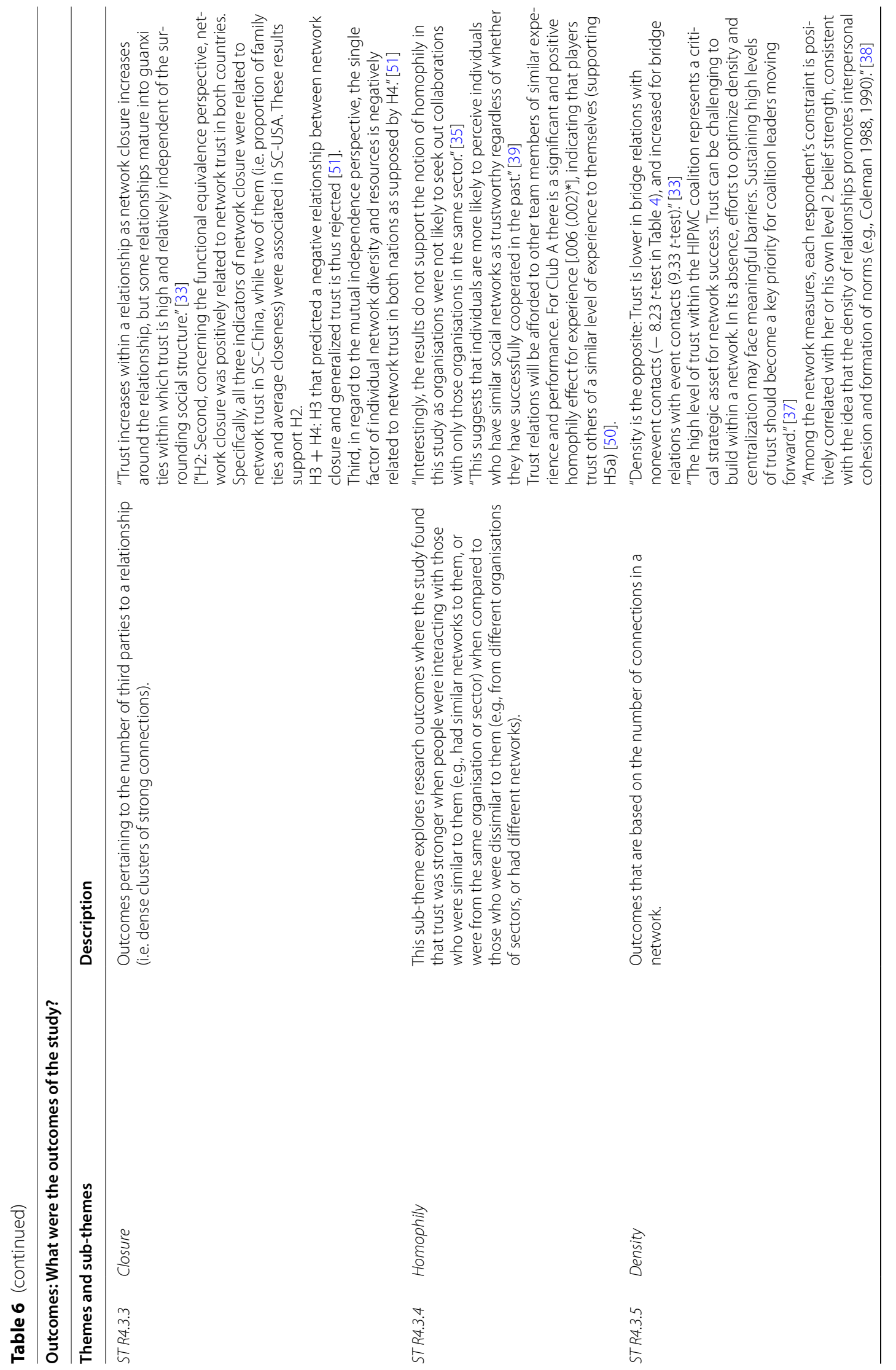




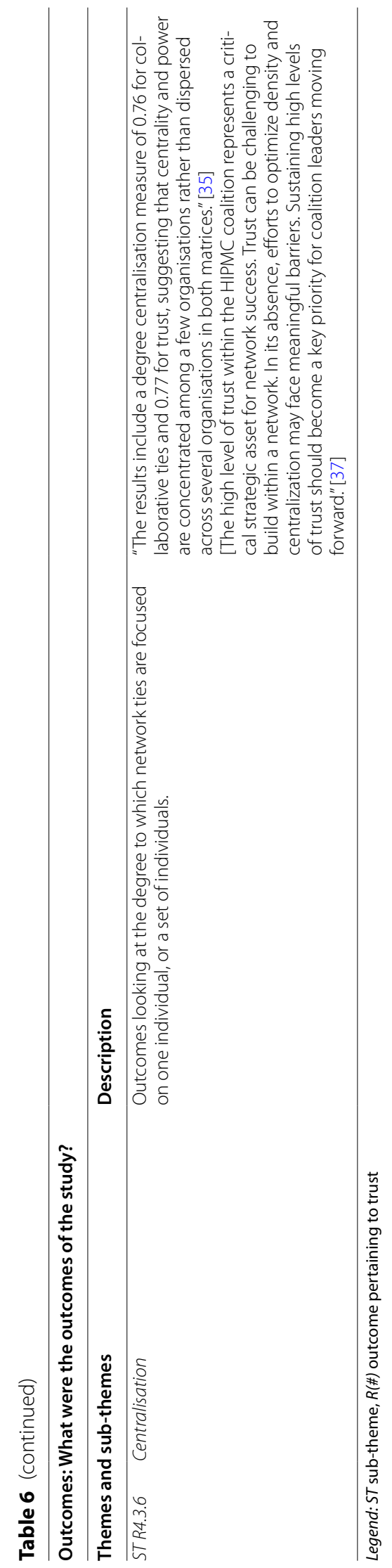


trust $[37,41,43,55]$. For example, a study by Neu, W [32] conceptualised trust comprehensively incorporating context, relational and complex concept into their conceptualisation of trust, while only tapping into the relational features when operationalising trust. Comparatively, Ferrin et al. [42] conceptualised trust only in terms of its relational features, but operationalised trust more comprehensively, including context-specific, relational, and features of social network analysis for the questions and indicators used.

Second, it would be valuable for future research to consider the issue of multidimensionality within partnerships and specifically appraise trust to see if it is operating as a context, mechanism and outcome, and is thus compatible with the realist perspective posited by Jagosh et al. [8] and further developed in Jagosh et al. [9] Indeed, our paper expands on this seminal work that understood trust to be a foundational element of partnership synergy but never further explored what the specific dimensions of trust were. Thus, our now enhanced understanding of trust as a context, mechanism, and outcome, affords researchers the opportunity to incorporate this knowledge to better understand why theories such as partnership synergy could lead to better partnership outcomes.

Finally, this review provides scope for prospective, longitudinal research to investigate and support trust in partnerships by paying specific attention to the multidimensionality of trust and thus identifying ways to improve trust as appropriate. For example, our enhanced understanding of trust reinforces the notion that trust, CBPR, and social networks constitute a conceptual triad, which is a valuable way to explore how partnerships can lead to better research outcomes. For example, in the CBPR conceptual model $[2,5]$ power dynamics are an important part of both the context and partnership process and are linked to trust in partnerships [57]. Using our enhanced understanding of trust, it may be possible to identify where power dynamics exist by identifying where asymmetrical trust relationships (a social network feature) are within the network. This shows the usefulness of exploring CBPR through a social-relational lens: network techniques can be employed to operationalise and measure the process and mechanisms that lead to success in CBPR.

\section{Limitations}

Although findings from this scoping review present an important perspective for which to approach future research, some limitations should be considered. As illustrated in the findings, trust is a complex concept that contains specific features and attributes that themselves are complex and could be further explored. With this in mind, we brought our perspective and understanding when interpreting themes throughout the literature, which may vary from how others interpret findings from the extracted literature included in this review. However, we tried to ensure rigour in this review by continuously engaging in discussions amongst each other to consider interpretations of the data from multiple perspectives. We also made use of a reflexive research journal, as suggested by Braun and Clarke [28], which incorporated thoughts and decisions made throughout the review, while exploring how our assumptions may have impacted reported themes. Another limitation is a lack of public and patient involvement, which is an optional additional stage according to Arksey and O'Malley [23], in the interpretation of our review results that may have added some additional insight to our findings. However, as this scoping review is the first stage in a larger collaborative research process, further consultation will take place with these and other stakeholders at subsequent stages of the project. Finally, some dynamics of trust may have been missed as the refined inclusion criteria incorporated only participatory health partnerships, as opposed to other kinds of community partnerships.

\section{Conclusion}

In conclusion, findings from this scoping review provide a comprehensive overview of how trust was conceptualised, operationalised, and measured and the outcomes of trust throughout social network and CBPR literature. Although there are important considerations to address when conducting research in this area, such as the complexity of trust as a concept, findings provide support for future research to incorporate trust as a lens to explore the social-relational aspects of partnerships.

\section{Abbreviations \\ PR: Participatory research; CBPR: Community-based participatory research; SN: Social network; SNA: Social network analysis.}

\section{Supplementary Information}

The online version contains supplementary material available at https://doi. org/10.1186/s13643-022-01910-x.

Additional file 1. CINAHL search strategy.

Additional file 2. PRISMA-SCR checklist.

Additional file 3. Individual study findings from the extracted literature.

\section{Acknowledgements}

We acknowledge the collaborating partners from the PPI Ignite@UL team for their contributions to the overall direction of this review. We would also like to acknowledge the Education and Health Sciences Faculty Librarian at the University of Limerick for helping to set up the search strategy for this scoping review and Jane O'Doherty for acting as the second reviewer.

\section{Authors' contributions}

All authors have made substantive intellectual contributions to the development of this scoping review. MG conceptualized the scoping review 
approach, lead the review, drafted, and edited the final manuscript. JS and AM secured funding, contributed to the conceptualisation of the review, participated in the review, and contributed to the writing and editing of the final manuscript. The authors read and approved the final manuscript.

\section{Funding}

This work was supported by the GEMS-10 scholarship from the University of Limerick (Ireland), and a scholarship from the Integrated Knowledge Translation Research Network (Canada: CIHR Foundation Grant; FDN \#143237). The parent study "PPI Ignite@UL" is funded by the Irish Health Research Board (HRB PPI-2017-009).

\section{Availability of data and materials}

The dataset used and analysed during the current study is available from the corresponding author on reasonable request.

\section{Declarations}

\section{Ethics approval and consent to participate}

Ethics is not required for this scoping review, although it is a component of a larger study that received ethical approval from the University of Limerick Education and Health Sciences research ethics committee (\#2018_05_12_EHS).

\section{Consent for publication}

Not applicable.

\section{Competing interests}

The authors declare that they have no competing interests.

Received: 4 December 2020 Accepted: 22 February 2022

Published online: 06 March 2022

\section{References}

1. Green LW, Canada RSo, Research BCfHP. Study of participatory research in health promotion: Review and recommendations for the development of participatory research in health promotion in Canada. Royal Society of Canada; 1995

2. Wallerstein N, Duran B, Oetzel JG, Minkler M. Community-based participatory research for health: Advancing social and health equity. Wiley; 2017.

3. Cargo M, Mercer SL. The value and challenges of participatory research: strengthening its practice. Annu Rev Public Health. 2008;29:325-50.

4. Kellogg W. Foundation Community Health Scholars Program Stories of impact. Ann Arbor: W K Kellogg Foundation Community Health Scholars Program; 2001.

5. Wallerstein N, Oetzel J, Duran B, Belone L, Tafoya G, Rae R. CBPR: what predicts outcomes? In 'Community-based participatory research for health: from process to outcomes, 2nd(Eds M Minkler, N Wallerstein) pp. 371-392. Jossey-Bass: San Francisco; 2008

6. Wallerstein N, Duran B. Community-based participatory research contributions to intervention research: the intersection of science and practice to improve health equity. Am J Public Health. 2010;100(S1):S40-S6.

7. Oetzel JG, Wallerstein N, Duran B, Sanchez-Youngman S, Nguyen T, Woo $\mathrm{K}$, et al. Impact of participatory health research: a test of the community-based participatory research conceptual model. Biomed Res Int. 2018;2018:1-12

8. Jagosh J, Macaulay AC, Pluye P, Salsberg J, Bush PL, Henderson J, et al. Uncovering the benefits of participatory research: implications of a realist review for health research and practice. Milbank Q. 2012;90(2):311-46.

9. Jagosh J, Bush PL, Salsberg J, Macaulay AC, Greenhalgh T, Wong G, et al. A realist evaluation of community-based participatory research: partnership synergy, trust building and related ripple effects. BMC Public Health. 2015;15(1):1-11.

10. Valente TW. Social networks and health: models, methods, and applications. Oxford University Press; 2010.

11. Scott J. Social network analysis. 4th ed. London: Sage Publications Ltd; 2017. p. 227.

12. Lyon F, Mšllering G, Saunders MN. Handbook of research methods on trust. Edward Elgar Publishing; 2015.
13. Luque JS, Tyson DM, Bynum SA, Noel-Thomas S, Wells KJ, Vadaparampil $\mathrm{ST}$, et al. A social network analysis approach to understand changes in a cancer disparities community partnership network. Ann Anthropol Pract. 2011;35(2):112-35.

14. Giandini RS, Kuz A. Social network analysis: a practical measurement and evaluation of Trust in a classroom environment. XVIII Congreso Argentino de Ciencias de la Computación; 2012

15. Salsberg J, Macridis S, Garcia Bengoechea E, Macaulay AC, Moore S, Committee KSTP. The shifting dynamics of social roles and project ownership over the lifecycle of a community-based participatory research project. Fam Pract. 2017;34(3):305-12.

16. Valente TW, Fujimoto K, Palmer P, Tanjasiri SP. A network assessment of community-based participatory research: linking communities and universities to reduce cancer disparities. Am J Public Health. 2010;100(7):1319-25.

17. Sherriff SL, Miller H, Tong A, Williamson A, Muthayya S, Redman S, et al. Building trust and sharing power for co-creation in Aboriginal health research: a stakeholder interview study. Evid Policy: J Res, Debate Pract. 2019;15(3):371-92.

18. Levula A, Harré M. Social networks and mental health: an egocentric perspective. Mental Health Rev J. 2016;21(3):161-73.

19. Kenny A, Hyett N, Sawtell J, Dickson-Swift V, Farmer J, O'Meara P. Community participation in rural health: a scoping review. BMC Health Serv Res. 2013;13(1):1-8.

20. Sherchan W, Nepal S, Paris C. A survey of trust in social networks. ACM Comput Surveys (CSUR). 2013;45(4):1-33.

21. Peters M, Godfrey C, Mclnerney P. Chapter 11: Scoping reviews, Joanna Briggs Institute Reviewer Manual [Internet]. Adelaide: The Joanna Briggs Institute; 2017.

22. Levac D, Colquhoun H, O'Brien KK. Scoping studies: advancing the methodology. Implement Sci. 2010;5(1):69.

23. Arksey H, O'Malley L. Scoping studies: towards a methodological framework. Int J Soc Res Methodol. 2005:8(1):19-32.

24. Gilfoyle M, MacFarlane A, Salsberg J. Conceptualising, operationalising and measuring trust in participatory health research networks: a scoping review protocol. BMJ Open. 2020;10(10):e038840.

25. Page MJ, Moher D. Evaluations of the uptake and impact of the Preferred Reporting Items for Systematic reviews and Meta-Analyses (PRISMA) statement and extensions: a scoping review. Syst Rev. 2017;6(1):263.

26. Nittas V, Mütsch M, Ehrler F, Puhan MA. Electronic patient-generated health data to facilitate prevention and health promotion: a scoping review protocol. BMJ Open. 2018;8(8):e021245.

27. Sandelowski M. Whatever happened to qualitative description? Res Nurs Health. 2000;23(4):334-40.

28. Braun V, Clarke V. Successful qualitative research: a practical guide for beginners. Sage; 2013.

29. Braun V, Clarke V. Using thematic analysis in psychology. Qual Res Psychol 2006;3(2):77-101.

30. Zhou S, Ng ST, Li D, Zhang J, Fan J, Yang Y. Characterizing stakeholders of aging-in-place through social network analysis: a study of Nanjing. China Sustainability (Switzerland). 2019;11(23):1-19.

31. Becker P. Dependence, trust, and influence of external actors on municipal urban flood risk mitigation: the case of Lomma Municipality, Sweden. Int J Disast Risk Reduct. 2018;31:1004.

32. Neu WA. Quantitative evidence of students' use of social networks and social categorization when self-selecting teams. J Market Educ. 2018;40(3):161.

33. Burt RS, Bian Y, Opper S. More or less guanxi: trust is $60 \%$ network context, 10\% individual difference. Social Netw. 2018;54:12.

34. N.M. Ardoin MLD, Connor TEP. The development of trust in residential environmental education programs. Environ Educ Res. 2017;23(9):1335.

35. Barnes M, Cousens L, MacLean J. Trust and collaborative ties in a community sport network. Managing Sport Leisure. 2017;22(4):310.

36. Kamya C, Shearer J, Asiimwe G, Carnahan E, Salisbury N, Waiswa P, et al. Evaluating global health partnerships: a case study of a gavi HPV vaccine application process in Uganda. Int J Health Policy Manag. 2017;6(6):327.

37. McCullough JM, Eisen-Cohen E, Salas SB. Partnership capacity for community health improvement plan implementation: findings from a social network analysis. BMC Public Health. 2016;16(1):1-11.

38. Moldoveanu MC, Baum JAC. I think you think I think you're lying: the interactive epistemology of trust in social networks. Manage Sci. 2011:57(2):393 
39. Lambright $\mathrm{KT}$, Mischen PA, Laramee CB. Building trust in public and nonprofit networks: personal, dyadic, and third-party influences. Am Rev Public Adm. 2010;40(1):64.

40. Milward HB, Provan KG, Fish A, Isett KR, Huang K. Governance and collaboration: an evolutionary study of two mental health networks. J Public Adm Res Theory. 2010;20(SUPPL. 1):i125.

41. Gürsakal N, Oǧuzlar A, Aydm ZB, Tüzüntürk S. Measuring trust in an intra-organisational context using social network analysis. Int J Manag Enterprise Dev. 2009;6(4):494.

42. Ferrin DL, Dirks KT, Shah PP. Direct and indirect effects of third-party relationships on interpersonal trust. J Appl Psychol. 2006;91(4):870.

43. Hamzeh J, Pluye P, Bush P, Ruchon C, Vedel I, Hudon C. Towards an assessment for organizational participatory research health partnerships: a systematic mixed studies review with framework synthesis. Eval Program Plann. 2019;73:116-28.

44. Dave G, Frerichs L, Jones J, Kim M, Schaal J, Vassar S, et al. Conceptualizing trust in community-academic research partnerships using concept mapping approach: a multi-CTSA study. Eval Program Plann. 2018;66:70.

45. Lucero J, Wallerstein N, Duran B, Alegria M, Greene-Moton E, Israel B, et al. Development of a mixed methods investigation of process and outcomes of community-based participatory research. J Mixed Methods Res. 2018;12(1):55.

46. Zoellner J, Hill JL, Brock D, Barlow ML, Alexander R, Brito F, et al. One-year mixed-methods case study of a community-academic advisory board addressing childhood obesity. Health Promot Pract. 2017;18(6):833.

47. Kathleen MGW. Researcher trustworthiness in community-academic research partnerships: implications for genomic research. Dissert Abstracts Int: Sect B: Sci Eng. 2018;79(1-B(E)):1-183.

48. Linda MM. How can non-government organizational perspectives inform community based participatory research in Malawi, Central Africa? Dissert Abstracts Int: Sect B: Sci Eng. 2010;70(10-B):6115.

49. Toran $\mathrm{JH}$. The effects of facilitation management on interorganizational coordination and trust in an anti-Iraq war political advocacy nonprofit network in the Twin Cities. Dissert Abstracts Int Sect A: Human Soc Sci. 2010;71(6-A):2222.

50. Dean L, Peter K, Garry R. Cooperative and competitive structures of trust relations in teams. Small Group Res. 2014;45(1):3.

51. Joonmo S, Qiushi F. In social capital we trust? Soc Indic Res. 2019;144(1):167.

52. Kolleck N, Bormann I. Analyzing trust in innovation networks: combining quantitative and qualitative techniques of social network analysis. Zeitschrift Fur Erziehungswissenschaft. 2014;17:9-27.

53. Bunt GG, Wittek RPM, Klepper MC. The evolution of intra-organizational trust networks - The case of a German paper factory: an empirical test of six trust mechanisms. Int Sociol. 2005;20(3):339-69.

54. Zolin R, Gibbons DE. Studying trust relationships using social network analysis. Handbook of Research Methods on Trust. 2nd ed; 2015. p. 189-97.

55. Julie EL. Trust as an ethical construct in community-based participatory research partnerships. Dissert Abstracts Int Sect A: Human Soc Sci. 2014;74(11-A(E)):1-231.

56. Weber LR, Carter A. On constructing trust: temporality, self-disclosure, and perspective-taking. Int J Sociol Soc Policy. 1998;18(1):7-26.

57. Wallerstein N, Muhammad M, Sanchez-Youngman S, Rodriguez Espinosa P, Avila M, Baker EA, et al. Power dynamics in community-based participatory research: a multiple-case study analysis of partnering contexts, histories, and practices. Health Educ Behav. 2019;46(1_suppl):19S-32S.

\section{Publisher's Note}

Springer Nature remains neutral with regard to jurisdictional claims in published maps and institutional affiliations. 